Portland State University

PDXScholar

$12-1-1992$

\title{
A Comparison of Developmental Sentence Score Patterns in Three Groups of Preschool Children
}

Michelle Lynn Riback

Portland State University

Follow this and additional works at: https://pdxscholar.library.pdx.edu/open_access_etds

Part of the Speech and Rhetorical Studies Commons

Let us know how access to this document benefits you.

\section{Recommended Citation}

Riback, Michelle Lynn, "A Comparison of Developmental Sentence Score Patterns in Three Groups of Preschool Children" (1992). Dissertations and Theses. Paper 4694.

https://doi.org/10.15760/etd.6578

This Thesis is brought to you for free and open access. It has been accepted for inclusion in Dissertations and Theses by an authorized administrator of PDXScholar. Please contact us if we can make this document more accessible: pdxscholar@pdx.edu. 
AN ABSTRACT OF THE THESIS OF Michelle Lynn Riback for the Master of Science in Speech Communication: Speech and Hearing Science presented December 1, 1992.

Title: A Comparison of Developmental Sentence Score Patterns in Three Groups of Preschool Children

APPROVED BY MEMBERS OF THE THESIS COMMITTEE:
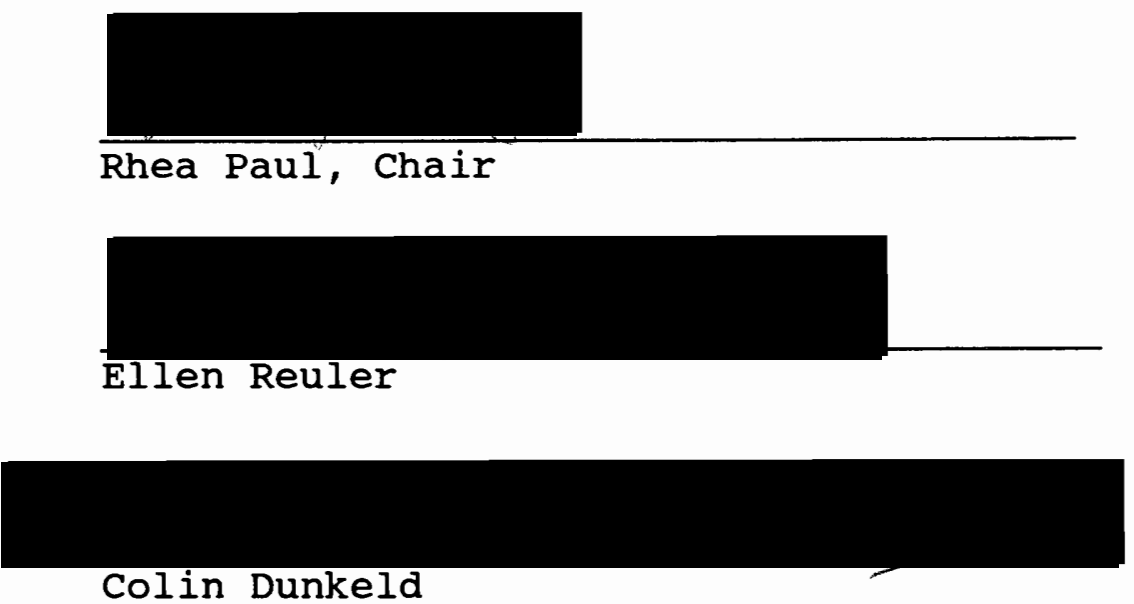

Researchers have successfully labeled specific patterns of expressive language development as it appears in children developing language normally. Little research has identified particular patterns of expressive language in children who display expressive language disorders or delays. Longitudinal studies of expressively language impaired children indicate that linguistic, educational and social impairments exist long after the language impairment was first identified (Aram, Eckelman and Nation, 1984; Aram 
and Nation, 1980; Fundudis, Kolvin and Garside, 1979; Stark, Berstein, Condino, Bender, Tallal and Catts, 1984). If patterns of delayed or disordered language development are researched and possibly labeled in the early stages of language development, strategies for assessment and intervention can be made more efficient and the effects of early language impairment on later academic achievement may be prevented.

The present study was part of the Portland Language Project, a longitudinal study of early language delay. Lee's Developmental Sentence Scoring (DSS) was used to attempt to identify syntactic patterns used by children exhibiting early language delay. The DSS is a standardized measure for analyzing children's standard English expressive language abilities in the following eight grammatical

categories: 1) indefinite pronouns; 2) personal pronouns; 3) main verbs; 4) secondary verbs; 5) negatives;

6) conjunctions; 7) interrogative reversal; and

8) Wh-Questions. Using the DSS, specific syntactical areas of deficit can be identified by analysis of an audiotaped speech sample.

A comparison of expressive language in the eight subcategories in the DSS was completed among three groups of preschool children; 1) children developing language normally (the NL group); 2) children who did not meet criteria for normal language development at 20 months, but later fell 
within the normal range of language development as measured by the DSS (Lee, 1974). This is referred to as the history of expressive language delay group (HELD); and 3) children who did not meet criteria for normal language development at 20 months and again, did not meet criteria for normal

language development as measured by the DSS (Lee, 1974) at later ages. This is referred to as the expressive language delay group (ELD).

The purpose of this study was to determine if significant differences exist in each of the eight subcategory group scores from the DSS between those children identified as expressively language delayed and those identified as developing language normally at ages three and four.

At age three, significant differences were found among the three groups in all eight subcategory scores of the DSS.

By age four, the significant differences were found between the delayed group and the normal developing group in the main verb category and the personal pronoun category only. There were no significant differences between the normal developing and the history of delay groups on any of the eight categories at age four.

The delayed group exhibited marked improvement and narrowed the deficits in expressive language to a specific area of language. 
The present study suggested that children with early language delay appear to "catch up" with normal peers in most areas of syntactic production by age four.

The DSS (Lee, 1974) provides information about specific areas of syntactic development. Due to the length and complexity of the DSS, it is not a tool that practicing clinicians often use. A study such as this may help the practicing clinician quickly screen a preschool child in a specific syntactic category, such as verb marking, in order to check for possible early language delay.

In addition to providing clinical assistance, this study has opened up the door for future research in syntactic development. This study could be expanded to examine the specific verb markers that are being used by the delayed subjects. This may lead to more efficient identification and remediation of early language delays. 
A COMPARISON OF DEVELOPMENTAL SENTENCE SCORE PATTERNS IN THREE GROUPS OF PRESCHOOL CHILDREN

by

MICHELLE LYNN RIBACK

A thesis submitted in partial fulfillment of the requirements for the degree of

\author{
MASTER OF SCIENCE \\ in \\ SPEECH COMMUNICATION : \\ SPEECH AND HEARING SCIENCE
}

Portland State University

1993 
TO THE OFFICE OF GRADUATE STUDIES:

The members of the committee approve the thesis of Michelle Lynn Riback presented December 1, 1992.
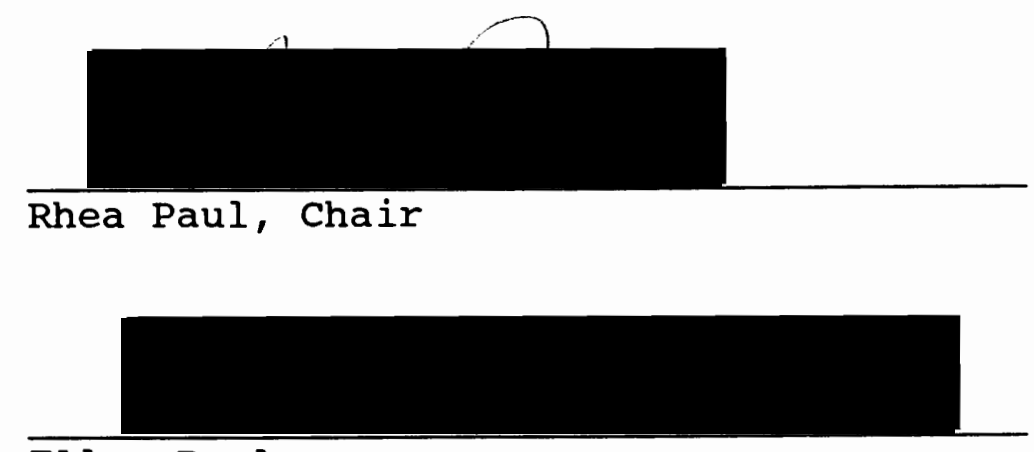

Ellen Reuler

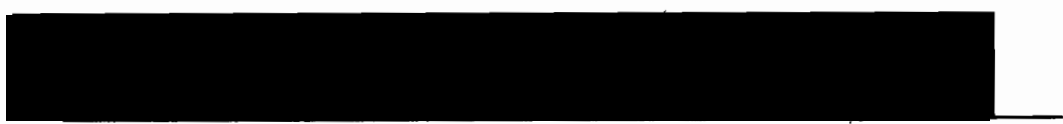

Colin Dunkeld

APPROVED :
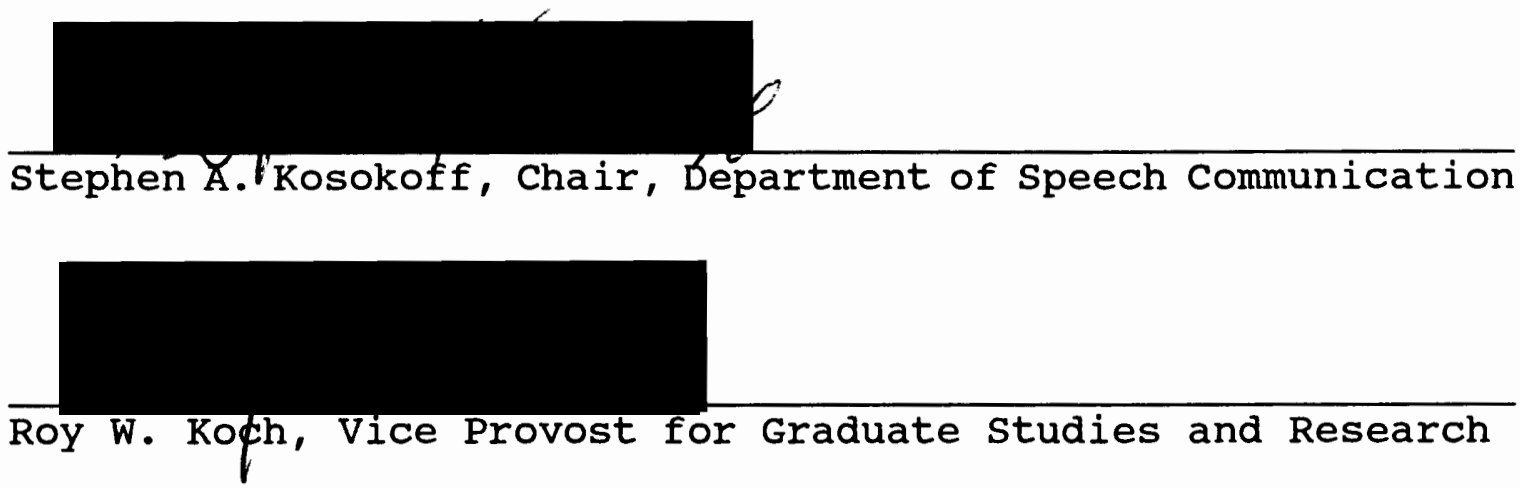


\section{ACKNOWLEDGEMENTS}

I wish to thank Dr. Rhea Paul for guiding and supporting me with expert advice in this project.

A special thank you to Ellen Reuler who so willingly and enthusiatically participated on my thesis committee.

I also want to thank Lisa McFarland who answered many of my repetitive questions and gave her time without hesitation. Finally, I feel very blessed and thankful for the constant support and encouragement that my husband, Jeff, gave to me during this project. He was there every step of the way with "pep talks" and listening ears. Thank you. 
TABLE OF CONTENTS

PAGE

ACKNOWLEDGEMENTS . . . . . . . . . . . . . . ii

LIST OF TABLES . . . . . . . . . . . . . . vi vi

CHAPTER

I INTRODUCTION . . . . . . . . . . . . 1

Statement of Purpose . . . . . . . . 4

Definition of Terms . . . . . . 5

II REVIEW OF THE LITERATURE . . . . . . . 7

Research on Developmental
Sentence Scoring. . . . . . 7

Research on Early Language Delay . . . 9

Syntactic Deficits in Early
Language Delay ...... 11

III METHODS AND PROCEDURES . . . . . . . . 13

Subjects . . . . . . . . . 13

Procedures . . . . . . . . . . 18

Instrumentation at Age Three and Age Four 19

Reliability .......... . 35

IV RESULTS AND DISCUSSION . . . . . . . 37

Results . . . . . . . . . 37

Discussion ........... 52

V SUMMARY AND IMPLICATIONS . . . . . . . 56

Summary . . . . . . . . . 56 
Implications . . . . . . . . . 57

REFERENCES • . . . . . . . . . . . . . . . . . . . 61 APPENDICES

A

B

C

D

$\mathrm{E}$

$\mathbf{F}$

G
QUESTIONNAIRE FOR PARENTS OF CHILDREN 15-30 MONTHS OLD . . . . . . . . 64

OREGONIAN ARTICLE • • • • • • • • • 66

PARENT PERMISSION FORM . . . . . . . 68

LANGUAGE DEVELOPMENT SURVEY • • • • • 70

DEVELOPMENTAL SENTENCE SCORE: SCORING CRITERIA •. . . . . . . 72

DEVELOPMENTAL SENTENCE SCORE: NORMS . . . . . . . . . . 75

HUMAN SUBJECTS RESEARCH REVIEW COMMITTEE APPROVAL MEMO •. . . . . . . 77 


\section{LIST OF TABLES}

TABLE

PAGE

I Summary of Demographic Data . . . . . . . 15

II Group Description: Age Three . . . . . . . 29

III Group Description: Age Four . . . . . . . 31

IV Subjects by Group Assignment:

Age Three and Age Four . . . . . . 33

$\checkmark$ Mean, Standard Deviation and Range

of Scores for Each Group on Each

DSS Category: Age Three . . . . . 38

VI Mean, Standard Deviation and Range

of Scores for Each Group on Each

DSS Category: Age Four . . . . . . . 40

VII Mean DSS Scores and Mean DSS Total

Points for Each Group:

Age Three . . . . . . . . . . . . . 42

VIII Mean DSS Scores and Mean DSS Total

Points for Each Group:

Age Four . . . . . . . . . . . . 4 43

IX ANOVA and Tukey Test Results: Age Three. . . 45

X ANOVA and Tukey Test Results: Age Four . . . 46 


\section{CHAPTER I}

\section{INTRODUCTION}

In the field of speech-language pathology, there has been extensive research completed to describe characteristics of normal language as it develops in young children. As a result of this research, specific patterns of expressive language development have been identified as consistent in normal children. However, not all children display these patterns of development. According to silva (1980), approximately $3-8 \%$ of the 3 year old population have language delay. Scarborough and Dorbrich (1990) found that some children displaying early language delay (ELD) in the preschool years displayed severe deficiencies later on in syntax, phonology, and/or semantics. By eight years of age three out of the four children they studied displayed severe reading disabilities directly attributable to the early language delay. Stark, Bernstein, Condino, Bender, Tallal and Catts (1984) reported that 6 out of 8 children in their study appeared to recover from early language delay, but only 2 of the 6 that appeared to recover were reading at age level later on. Preschoolers with early language delay are at risk for later language and academic problems (Aram and Nation, 1980; Hall and Tomblin, 1978; Paul and Cohen, 1984). 
Early language deficiencies persist into the school years and may have a negative impact on later academic performance. Therefore, it is important to identify patterns of impairment within the different types of language disorders and delays. These patterns will help the clinician to better differentiate between what is called a disorder and what is called a delay. If specific patterns of deficit can be labeled, remediation for specific language deficits will follow to curtail ELD and, therefore curtail the effects that ELD has on later academic achievement.

Leonard (1986) differentiates between language disorder and language delay. A language disordered child will use some feature of language that normally developing children may exhibit at some point in their development, but the feature is used more frequently and in contexts that are not seen in the normal pattern of development (Leonard, 1986). For example, a child may use the syntactically correct -ing ending, but not use the /s/ ending. This pattern is not found in the normal developing child. A child with a language delay follows the normal sequence of language development, but follows the sequence more slowly than other children his/her age. For example, a normal child may acquire two-word combinations at 18 months of age, whereas a child with a language delay generally will not acquire the same general two-word combinations until approximately 40 months of age (Leonard, 1989). 
Formal standardized tests exist to assess if a child's language abilities fall within the normal range of language development for his or her age. However, these tests do not give specific information regarding the type and patterns of the deficit. These tests tell us if the child's language development is different from that of his/her peers. If a child does not fall within the normal range of language development, the child is said to have a language disorder or a language delay.

once the formal, standardized tests identify a child as language disordered or language delayed, how does one differentiate between what constitutes a language disorder and what constitutes a language delay? How does one identify particular areas of deficit? One valuable procedure that may be used to help answer these questions and is widely used to assess a child's expressive language abilities is the Developmental sentence scoring (DSS) developed by Lee (1974). This procedure involves analysis of an audiotaped speech sample which occurs in an environment closely matched to the child's natural speaking environment.

The DSS is a tool for analyzing children's standard English expressive language abilities in eight specific grammatical categories. The authors of the DSS developed and provided normative data with weighted scores and percentile ranks for an examiner to use to estimate children's overall 
syntactic abilities. Those abilities are then compared with other children the same age.

While extensive information has been derived from research studies regarding normal language development, there is a need to identify particular patterns of deficit in the different types of language disorders and delays. More research is necessary to define patterns of disorder and delay. A study using the DSS can help distinguish between the language delay and the language disorder, help to identify such patterns and eventually it is hoped, lead to more effective intervention.

\section{STATEMENT OF PURPOSE}

The purpose of this study was to determine if significant differences exist in each of the eight subcategory group scores from the DSS for three diagnostic groups at age three and at age four. The following groups were included and compared in the study:

1. Children developing language normally.

2. Children who did not meet criteria for normal development at 20 to 34 months, but later fell within the normal range of language development as measured by the DSS (Lee, 1974). This group is referred to as the history of language delay group (HELD).

3. Children who did not meet criteria for normal language development at 20 to 34 months and again, did not meet 
criteria for normal language development as measured by the DSS (Lee, 1974) at later ages. This group is referred to as the expressive language delay group (ELD).

The specific research questions were:

1. Are there significant differences in the Developmental sentence scoring subcategory scores among the normal, history of delayed, and delayed children?

2. Do significant differences exist between the normal group and the history of delay group and/or the delayed group in any of the eight DSS subcategories?

3. If so, do these significant differences remain constant at age three and age four?

\section{DEFINITION OF TERMS}

The following definitions will be utilized throughout this study:

1. Expressive Language Delayed (ELD) Subjects.

Subjects who were Late Talkers because they produced

fewer than 50 words by parent report on the LDS at 20

to 34 months of age and scored below the tenth

percentile on the DSS at ages three and four.

2. Normal Language Subjects.

A. At 20 to 34 months:

Children 20 to 34 months of age and producing more than fifty different words. 
B. At age three and four:

Children 36 to 48 months of age with a DSS score above the tenth percentile for chronological age.

3. History of Lanquage Delay (HELD) Subjects.

At 20 to 34 months were considered Late Talkers

because they produced fewer than fifty different words, but at age three and four scored above the tenth percentile in terms of DSS score. 
CHAPTER II

\section{REVIEW OF THE LITERATURE}

This study focuses on the use of the DSS to identify specific areas where consistent deficits in expressive language might occur. These areas may be used to identify patterns of syntactic deficit and to determine whether these patterns are consistent over time.

Information regarding the grammatical categories contained in the DSS will be discussed as well as the normative data collected on the DSS by Lee and Canter (1971). In addition, literature that identifies deficits commonly seen in the syntax of ELD children will be reviewed.

\section{RESEARCH ON DEVELOPMENTAL SENTENCE SCORING}

Lee \& Canter (1971) developed normative data for the DSS. To do this, they gathered speech samples from 80 boys and 80 girls aging from 3 years, 0 months to 6 years, 11 months. These children were equally distributed within 6 month age groups. The children has scores of 85 to 115 on the Peabody Picture Vocabulary Test and they were from middle income, English speaking homes. An audiotaped speech sample was taken by an examiner interacting verbally with 
the child. The last 50 sentences in the speech sample were then analyzed using the DSS. The scores for each 6 month age distribution were given percentile values and distributed normally to obtain percentiles at $90,75,25$, and 10. These percentiles should be used as guidelines of expressive performance to be used for comparison of children within the same age groups.

Interscorer and intrascorer reliability for the DSS was completed. Twenty-four speech-language pathology students, who were formally trained to score the DSS, were each given a different speech sample audiotape. Each student transcribed 50 sentences from the tape. The discrepancies between the student's scoring and the author's scoring ranged from .62 points above and .72 points below, with an overall discrepancy of $3 \%$ (Lee \& Canter, 1971). This minute discrepancy demonstrates that with proper training, that examiners will consistently choose the proper sentences to score and score them correctly. In addition, the author then scored each of the student's transcribed sentences. The overall discrepancy between scores was $2 \%$. The DSS was found to be a reliable norm referenced measure of whether a child falls within the normal range of syntactic abilities. It is a tool for analyzing verbal performance as well as planning specific areas of remediation. 


\section{RESEARCH ON EARLY LANGUAGE DELAY}

According to McNeil (1970) and Brown (1973), the period that base syntax is most actively learned is between 18 months and 4 years of age. If expressively language delayed children can be identified early by specific deviant and/or slow patterns of syntactic development, remediation can begin at an early age. Scarborough and Dorbrich (1990), suggest that early intervention is important due to the academic problems children with early language delay (ELD) may exhibit later in life. They studied the longitudinal development of 4 children classified as having ELD in their preschool years (2 $1 / 2$ to 5 years of age). All four children had severe deficiencies in expressive syntax, phonology, and semantics at age two to three. By age 5, these children were found to have normal or near normal language skills. Scarborough and Dobrich (1990) refer to this as "Illusory Recovery." By age 8,3 out of 4 ELD children were found to have severe reading disabilities. It is suggested that this negative outcome is directly attributable to the children's early language delay (Scarborough \& Dobrich, 1990). The apparent recovery from ELD to normal does not mean that future reading abilities will necessarily be normal.

Several longitudinal studies conclude ELD children have a high rate of linguistic problems that persist many years after these children are originally diagnosed (Bishop 
\& Edmundson, 1987; Aram, Eckelman and Nation, 1984;

Fundudis, Kolvin and Garside, 1979; Stark, et al., 1984). Bishop and Edmundson (1987) attempted to identify the children who most likely would have persistent language disorders and those children whose disorders are "transient." Their study followed the same 87 children each at four, four and one-half, and five and one-half years of age. When compared to their normal peers, they found that by five and one-half years old, the language disorder had been cleared up. The explanation may be that by this age, the normal children have slowed down in development of new language forms. This may give the ELD children time to catch up. Bishop and Edmundson, (1987) were able to predict prognosis of persistent impairment for individual children with or without a language impairment with $90 \%$ accuracy on the basis of language testing completed at four years of age. In examining the effects of preschool phonological disorders on subjects first in grade school, then in adolescence, and finally in adulthood, Lewis and Freebairn (1992) found that those who had language impairment with the speech impairment performed worse on reading and spelling measures than those who only displayed a speech deficit at the preschool level. Those displaying the concomitant language impairment at the preschool level, later displayed lower reading and spelling skills. In addition, Maxwell and Wallach (1984) found that written skills such as spelling 
and reading are very common areas where children with early language impairment have difficulty. The literature shows that early language delay often has long-term effects on learning even when child appears to "grow out of" the oral language deficits. Knowing more about oral language problems and how they change with time could help us understand the relation between early language delay and later language problems.

\section{SYNTACTIC DEFICITS IN EARLY LANGUAGE DELAY}

According to Leonard (1989), children with a language impairment show consistent problems with specific syntactic forms. Some forms mentioned include grammatical morphemes (plural /s/, regular past -ed, possessive /s/ and third person singular /s/), articles, copula be, auxiliary be, modal will, contractible morphemes, and irregular past verb forms.

Like Leonard (1989), Rescorla and Schwartz (1990) attempted to identify specific areas of deficit in disordered children. However, their study involves a diagnosis and follow-up of the same group of 25 males aged 20 to 31 months diagnosed as having specific expressive language delay (SELD). To be diagnosed as having SELD in their study, the boys had to have fewer than a 50 word vocabulary, few word combinations, and be 5 months below their chronological age on the Reynell Expressive Language 
Scale (Reynell, 1984). At follow-up, 8 months later, approximately $50 \%$ of the 25 boys still had poor expressive language. However, almost all of the 25 boys still had problems with syntactically complex and morphologically correct language. Deficits were found in use of copula, auxiliary verbs, past tense inflections, and pronouns.

The present study will look at the areas of syntactic deficit in subjects similar to those in the Rescorla and Schwartz study, and will attempt to describe syntactic development and compare patterns of deficits seen to those found by Rescorla and Schwartz as well as by Leonard. 
CHAPTER III

METHODS AND PROCEDURES

SUBJECTS

This study derives from the Portland Language Development Project, a longitudinal study of early language delay.

Subject Description at Intake: 20 to 34 Months

Subjects in the Portland Language Development Project were recruited when they were between 20 and 34 months of age from three sources: 1) pediatric clinics in the Portland Metropolitan area; 2) responses to a Portland radio broadcast request for expressively language delayed children, and 3) responses to a newspaper article in the oregonian requesting similar subjects. (See newspaper article in Appendix B.) The Human Subjects Review committee approved all procedures for the longitudinal study. Approval was granted by the Human Subjects Research Review Committee to conduct this study which utilizes information on human subjects. (Please see Appendix $G$ for the approval memo.) At intake into the study, parents of all the subjects signed a permission form and filled out questionnaires regarding parental occupation(s), their child's birth date, and the 
number of words their child used, and if their child formed short sentences with those words.

At intake, two diagnostic groups were formed: normal language (NL) and late talkers (LT). The children in the normal group were reported by their parents to use more than fifty different words on the Language Development Survey (LDS) (Rescorla, 1989). The subjects were considered LT if they used fewer than fifty different words by parental report on the LDS. The LDS is a questionnaire with a checklist of containing 300 of the most common words in children's early vocabularies. Space is also provided on the LDS questionnaire to record the child's three longest utterances. The groups were matched for chronological age and were matched as closely as possible for race, sex, and socioeconomic status (determined by using a four factor scale by Myers \& Bean, 1968). (See Table I.)

Twenty-two subjects from the normal language (NL) group and nineteen subjects from the LT groups served as subjects for the present study. The mean age of the normal group at intake into the Portland Language Development Project was $25.85+/-4.24$ months with a mean vocabulary size of $224.66+/-62.90$ words. The mean age at intake of the late talker group was $25.45+/-3.91$ months with a mean vocabulary size of $28.35+/-26.78$ words. Table I displays demographic data on the subjects involved in this study. At 
TABLE I

SUMMARY OF DEMOGRAPHIC DATA

\begin{tabular}{|c|c|c|c|c|c|c|}
\hline Group & $n$ & $\begin{array}{l}\text { Mean Age (and SD) } \\
\text { in Months }\end{array}$ & $\begin{array}{l}\text { Mean SES } \\
\text { (and SD) }\end{array}$ & Race & Me & $\begin{array}{l}\text { an LDS Vocabulary } \\
\text { Size (and SD) }\end{array}$ \\
\hline Normal & 22 & $(4.24)$ & $2.43 *(1.4)$ & $\begin{array}{l}\text { 95\%White } \\
\text { 5\%Minority }\end{array}$ & $\begin{array}{l}58 \% \text { Male } \\
42 \% \text { Female }\end{array}$ & $224.66(62.9)$ \\
\hline $\begin{array}{l}\text { Late } \\
\text { Talker }\end{array}$ & 19 & $25.45(3.91)$ & $3.0 *(.9)_{1}$ & $\begin{array}{l}\text { 85\%White } \\
\text { ginority }\end{array}$ & $\begin{array}{l}70 \% \text { Male } \\
30 \% \text { Female }\end{array}$ & $28.35(26.8)$ \\
\hline
\end{tabular}

*Based on Hollingshead's four factor measure of social position on a scale from 1 to 5 , with 1 being the highest socioeconomic status and 5 being the lowest. (Myers and Bean, 1965) 
intake evaluation, all subjects completed and passed a hearing screening at $25 \mathrm{~dB} \mathrm{HL}$, and scored 85 or more on either the Bayley scales of Infant Development (Bayley, 1969 ) or the stanford-Binet Intelligence Scale (Terman \& Merril, 1960) depending on their ages. The subjects had no known physical handicaps, mental retardation, or autism (Paul and Shiffer, 1991).

Follow-up Assessment: Ages Three and Four

The subjects were seen again at ages three and four as part of their participation in the longitudinal study. At each of these evaluations, a spontaneous speech sample was collected from each subject while engaged in free play with his/her parent in a clinic room at Portland state University. At the four year evaluation, children also received hearing screening at $20 \mathrm{~dB}$, using ASHA (1985) guidelines. All subjects passed this screening.

Criteria for Language Diagnostic Group Assignment: Age Three

The criteria for establishing the language status of the subjects at the three year old follow-up were:

1. The subjects were considered to be in the normal language (NL) group if they used more than fifty different words at 20 to 34 months as reported by their parents on the LDS and also scored above the tenth percentile on the Developmental Sentence Scoring (DSS) (Lee and Canter, 1971) calculated from a free speech sample collected during the 
follow-up assessment at age three. All subjects in the normal language group scored above the tenth percentile on the DSS at both ages three and four $(n=22)$.

2. The subjects were considered to be in the history of expressive language delay (HELD) group if they were identified as LT at 20 to 34 months but at age three scored within the normal range of productive language in terms of the DSS scores (above the tenth percentile) $(n=8)$.

3. The subjects were considered to be in the expressive language delayed (ELD) group if they were identified at 20 to 34 months as LT and also scored below the tenth percentile on the DSS at age three $(n=11)$.

Criteria for Language Diagnostic Group Assignment: Age Four

1. The subjects were considered to be in the normal language (NL) group if they used more than fifty different words at 20 to 34 months as reported by parents on the LDS and also scored above the tenth percentile on the DSS at age four. All subjects in the normal language group scored above the tenth percentile on the DSS at both ages three and four $(n=22)$.

2. The subjects were considered to be in the history of language delay (HELD) group if they were identified as LT at 20 to 34 months and scored above the tenth percentile at age four $(n=12)$.

3. The subjects were considered to be in the expressive language delayed (ELD) group if they were 
identified as LT at 20 to 34 months and also scored below the tenth percentile on the $\underline{\text { DSS }}$ at age four $(n=7)$.

\section{PROCEDURES}

Collecting and Analyzing the Speech Sample: Age Three and Four

A Sony BM-80 Dictator/Transcriber tape recorder with a Sony DC-30N, 30-minute dictation cassette was used to audiotape each ten minute parent/child interaction in each evaluation period. Parents at both sessions were given a standard set of pretend play materials and told to "play with these toys with your child as you would at home." The Electret Condenser solar ECM-D8, Imp 16kQ microphone was attached to the tape recorder and placed near the parent/child play area.

All evaluations at each age level were completed in a small classroom at Portland State University. The parentchild interaction was audiotaped by a graduate student in speech-language pathology. The subject and parent were audiotaped while playing with common toys on the carpeted area of the small classroom. The common toys included the Fisher Price house, Fisher Price people, Fisher price furniture, Fisher Price automobiles, Duplo blocks, and play dishes and eating utensils. The toys were the same for both the three and four year samples

A trained graduate research assistant who was present during the collection of the sample transcribed each 
audiotaped speech sample. The transcription was then analyzed by a trained graduate assistant according to the Developmental sentence Scoring. All graduate assistants are trained in the procedures and rules of the DSS outlined by Lee $(1974)$.

\section{INSTRUMENTATION AT AGE THREE AND AGE FOUR}

The DSS (Lee \& Canter, 1971) was used to analyze the spontaneous speech samples of each subject at each evaluation period. The DSS is a standardized measure which assesses the syntactical structure of the subject by assigning weighted scores to complete sentences. A complete sentence must consist of $a$ noun and $a$ verb in a subjectpredicate relationship. It is recommended that fifty sentences for each subject be analyzed.

The syntactic structures that are scored in the DSS include indefinite pronouns or noun modifiers, personal pronouns, main verbs, secondary verbs, negatives, conjunctions, interrogative reversals, and Wh-questions (Lee, 1974). Weighted scores are assigned to each of these classifications based on what Lee (1974) has observed to be the developmental order of each classification. The lowest score possible for each classification is one; and the highest score possible is eight. 
Procedures for Computing Developmental Sentence Score

A spontaneous speech sample is collected during a parent/child interaction with various toys. The interaction is audiotaped and transcribed into typed transcripts, following directions recommended by Lee (1974). A corpus of fifty intelligible, different sentences is necessary to use the DSS procedure. Sentences that were selected contained a subject and a verb, but did not have to be grammatically correct (Lee, 1974). Each sentence is analyzed and given a score (following the rules described by Lee) based on the following eight categories: 1) indefinite pronouns and/or noun modifiers, 2) personal pronouns, 3) main verbs, 4) secondary verbs, 5) negatives, 6) conjunctions, 7) interrogative reversals, and 8) Wh-questions. These eight categories have been shown by Lee \& Canter (1971) to be most developmentally significant in children's language acquisition.

The DSS procedure allows scores from 1 to 8 in each category. A higher score is obtained for structures requiring more complex syntactic development (Lee, 1974). Please refer to Appendix E for examples of the points possible within each grammatical category. Before scoring, the examiner must keep in mind that the sentences should be analyzed in context of their semantic unit and not analyzed word by word. 
The first grammatical category of "indefinite pronouns or modifiers" allows scores for it, this, and that. According to Lee (1974), these words obtain a score of 1 because they appear early in a child's repertoire. In this category, the word can be used as a pronoun or a noun modifier and still receive the same score. For example, the pronoun this is given the score of 1 in both of the following sentences: "This is a cat" and "I want this cat." To obtain a score of three, a sentence must contain one or more of the following indefinite pronouns: no, some, more, all, $\operatorname{lot}(s)$, one(s), two, three, (etc.), other(s), another, something, somebody, someone. A score of 4 is given for: nothing, nobody, none, no one. Indefinite pronouns or modifiers are not assigned to score groups of 2, 5, and 6 since, compared to the other categories, specific pronouns are not developing at times equivalent to these scores. The remaining words which receive a score of 7 include: any, anything, every, everything, anybody, anyone, everybody, everyone, both, few, many, each, several, most, least, much, next, first, last, second, (etc.) According to Lee (1974), indefinite pronouns or modifier vocabulary development is fairly complete before vocabulary in the other seven categories are completed. For this reason, a score of 8 is not available for this category.

The second category that is analyzed in the DSS is the personal pronoun category. A score of 1 is given to the 
Ist and 2nd person personal pronouns: I, me, my, mine, you, your(s). These pronouns are considered easier and acquired earlier because distinctions of case and/or gender are not required (Lee, 1974). To obtain a score of 2 through 8 , case, gender, and/or number distinctions are necessary. Plural pronouns receive a score of 3 . They are: we, us, $\operatorname{our}(\mathrm{s})$, they, them, their, these, those. Lee (1974) did not assign personal pronouns a score of 4 . The reflexives myself, yourself, himself, herself, itself, themselves, and ourselves receive a score of 5. Reflexive pronouns do not appear simultaneously and occur very infrequently. For these reasons, Lee placed all reflexives in the same group. Wh-pronouns and the Wh + infinitive receive a score of 6 due to their increased complexity. Wh-pronouns include: who, which, whose, whom, what, that, how many, how much. The following personal pronouns receive a score of $7:$ his, own, one, oneself, whichever, whoever, whatever. Lee (1974) does not include assign personal pronouns to the score of 8 .

The next category that is considered on the DSS is the "main verb" category. Scores of 3 and 5 are not assigned to main verbs (Lee, 1974). The following structures receive a score of 1: uninflected verbs as in the sentence "I like you;" copula is or 's as in the sentence "It's mine;" and the present progressive verb (is + verb + ing) as in "She's swimming." These forms are all scored with a 1 because they appear earliest in most young 
children's repertoire (Lee, 1974). A score of 2 is given to $\underline{-s}$ and -ed verb endings (walks, walked), irregular past verbs (broke, woke), and the copula (am, are, was, were). 4 is assigned to the following main verbs: 1) can, will, may + verb as in "will come;" 2) the obligatory do + verb as in "don't hit;" and 3) the emphatic do + verb as in "They do eat." The following get a score of $6:$ 1) could, would, should, might + verb as in "should go" and "could come;" 2) obligatory does, did + verb as in "She really does exercise" and "They really did go to the game;" and 3) the emphatic does, did + verb as in "She does like to go" and "he did eat." The following receive a score of $7: 1$ ) passives with get or be (in any tense), as in "They were to get A's on their tests" and "He was to be punished;" 2) must, shall + verb as in "shall play;" 3) have + verb + en as in "I have seen;" and 4) have got as in "They have got." The main verb category allows for a score of 8 if the child's expressive language falls within the following criteria. The child must say: 1) have (or had) been + verb + ing as in "have been eating" or "had been eating;" 2) modal + have + verb + en as in "may have been eating;" 3) modal + be + verb + ing as in "would be sitting;" or 4 ) other auxiliary combinations such as "should have been sitting."

The next category that is scored is "secondary verbs." Secondary verbs are more syntactically complex. Two sentences are put together by infinitives, participles, 
or gerunds (Lee, 1974). Therefore, the child will receive a score in the main verb category as well as this category. Secondary verbs are not given scores of 1 or 6 . A score of 2 is given for the five early developing infinitives wanna ("I wanna go"), gonna ("I'm gonna eat"), gotta ("I gotta go"), lemme ("Lemme [to] play"), and let's ("Let's [to] play"). Non-complementing infinitives receive a score of 3. Non-complementing infinitives are described by Lee (1974) as a sentence that is complete without the infinitive. For example, the sentence "Ice cream is good to eat" would be complete without the "to eat." The sentence "Ice cream is good" would still make sense. Therefore, the infinitive "to eat" is non-complementing. The present or past participles receive a score of 4. Early infinitive complements with differing subjects in kernel, later infinitive complements, obligatory deletions, and infinitives with a wh- word receive a score of 5 . Some respective examples are "I want him to play," "I had to go," "Make him [to] play," and "I know what to buy." The passive infinitive complements with get and be receive a score of 7 . Examples are: "I have to get dressed" and "I have to be pushed" (Lee, 1974). Gerunds such as "Playing is fun" and "He started playing" receive a score of 8 in this secondary verb category.

The fifth DSS category that is scored is the "negatives" category. It, this, that + copula or auxiliary 
is, Is + not receive a score of 1 . Examples are "This is not mine" and "It's not red." scores of $2,3,6$, and 8 are not applicable within this category. Use of can't and don't receive a score of 4 ; and isn't and won't receive a score a 5. All other negatives that the child uses are scored with

a 7. These include uncontracted negatives, pronoun auxiliary or pronoun copula contractions, and auxiliary + negative or copula + negative contractions.

"Conjunctions" are the sixth category that are scored on the DSS. $1,2,4$, and 7 do not apply in this category. Use of and receives a score of 3 . The following conjunctions receive a 5: but, so, and so, so that, or, if. A score of 6 is given to the conjunction because. The remaining conjunctions such as where, when, how, while, until, (etc.) receive an 8. Obligatory and elliptical deletions, and Wh-words + infinitive receive a score of 8 as we11.

The next category, "interrogative reversals," are scored with a $1,4,6$, or 8 . The earliest form of interrogative reversal that young children acquire is the reversal of the copula as in "Are you Shelley?" These reversals are scored with a 1 . Reversal of the auxiliary be is scored 4, as in "Is she coming?" More complex reversals are scored with a 6. They include: 1) obligatory do, does, did ("Do you want to go?"); 2) the reversal of the modal ("Can you go with us?"); and 3) tag questions ("It's great, 
isn't it?"). The following reversals are even more complex and score 8: 1) reversal of the auxiliary have ("Have you got the time?"); and 2) reversal of more than one auxiliary ("Have you been there?").

The last category that Lee (1974) includes in the DSS is scoring of "Wh-questions." Wh-questions are scored when an appropriate wh-word is placed at the beginning of the sentence. The wh-word may be the subject in the sentence. However, if there is a reversal of the interrogative, the sentence is scored in both categories (Lee, 1974). For example, "What is he doing?" is scored in the wh-question category because the word what is in the initial position of the sentence; and is he is scored as an interrogative reversal. Wh-questions are scored with $2,5,7$, or 8 . A score of two may be obtained when the child uses who, what, what + noun, where, how many, how much, what - do, or what for. Some examples are: "Where are you going?," "What are those keys for?", and "How much do you have?" The subject is able to receive a score of 3 when how + adjective, how, and when are used in the initial position of the sentence. The following wh-word combinations receive a score of 7 : why, what if, how come, how about + gerund ("How about going to the store?"). The later developing wh-word receive a score of 8 . They are: whose, which, and which + noun as in "Whose jacket is that?" or "Which car are we going in ?" 
Lee (1974) noted that not all of the possible developmental syntactical forms are included in the DSS. Therefore, the sentence point is included as a possible way for children to receive credit for adult-like forms. Before scoring each syntactic structure, the examiner must read the sentence and decide if it is a socially correct, adult-like form. A sentence point is then added to the point total for each adult-like sentence.

In addition, the use of the attempt mark is very important when scoring the DSS. An slash mark or an "attempt mark" is included instead of a point score when a particular structure is attempted, but lacks the proper feature. For example, "Her is swimming" calls for an attempt mark in the personal pronoun category because the correct personal pronoun in the sentence is "she." The subject did attempt a personal pronoun, but used the wrong one. This structure is not yet acquired. Therefore, any sentence containing an attempt mark should not receive a sentence point. The attempt mark helps the examiner to instantly identify the specific mistakes the subject is making as well as identify patterns of the mistakes (Lee, 1974)

Once a score for each of the fifty sentences is obtained, the developmental sentence score is computed by adding all sentence scores and dividing by 50 . 
overall, the DSS is a comprehensive measure which evaluates a wide range of syntactic structures as well as give credit for acceptable sentences that may not contain the categories scored on the DSS.

\section{Diagnostic Group Assignments: Age Three}

The mean age of the subjects with language skills falling into the normal range (NL) was 37.4 months with a standard deviation of 1.8 months and a range of 36 to 42 months of age. All 22 subjects originally diagnosed as NL remained in the NL group. of the children originally diagnosed as LT, $8(42 \%)$ scored above the tenth percentile on the DSS at age three. The mean age of the subjects with language skills delayed at 20 to 34 months, but above the tenth percentile on the DSS at age three (HELD-3) was 37.1 months with a standard deviation of 2.4 and a range of 36 to 43 months of age. Of the 19 subjects diagnosed as toddlers as LT, 11 (58\%) were considered ELD at age three. The mean age of the subjects who displayed delayed language at 20 to 34 months and scored below the tenth percentile on the DSS at three years of age $(E L D-3)$ was 38.7 months with a standard deviation of 2.9 months with a range of 36 to 44 months. (See Table II.)

\section{Diagnostic Group Assignments: Age Four}

All subjects originally diagnosed as NL scored above the tenth percentile on the DSS at age four. The mean age 
TABLE II

GROUP DESCRIPTION: AGE THREE

\begin{tabular}{|c|c|c|c|}
\hline Group & $\underline{\mathbf{n}}$ & $\begin{array}{l}\text { Mean and } \\
\text { (SD) Age } \\
\text { in Months }\end{array}$ & $\%$ Male \\
\hline Normal (NL) & 22 & $(1.8)$ & $59 \%$ \\
\hline History of Delay (HELD-3) & $8(428)$ & $(2.4)$ & $88 \%$ \\
\hline Delayed (ELD-3) & $11(58 \%)$ & $(2.9)$ & $54 \%$ \\
\hline
\end{tabular}


of the subjects with language skills falling into the normal range at four years of age (NL) was 50.3 months with a standard deviation of 2.4 months and a range of 48 to 57 months of age. of the children originally diagnosed as LT, 12 (63\%) were considered HELD at age four. The mean age of the subjects with language skills delayed at 20 months, but above the tenth percentile on the DSS at age four (HELD-4) was 49.5 months with a standard deviation of 1.6 and a range of 48 to 53 months of age. The mean age of the subjects who displayed delayed language at 20 months and scored below the tenth percentile at four years of age (ELD-4) was 52.6 months with a standard deviation of 2.4 months with a range of 49 to 55 months. These data are shown on Table III.

\section{Diagnostic Group Composition at Ages Three and Four}

A total of 19 children diagnosed at intake as LT were included in either the history of delay group or the delayed group at age three or age four. All met criteria at age 20 to 34 months for slow expressive language development as discussed above. At three year evaluation, 8 subjects, 7 male and 1 female, were placed in the history of delay group (HELD-3). They did not meet criteria for normal expressive language at 20 to 34 months, but at age three met criteria for normal language according to Lee's (1974) DSS scoring. Eleven subjects, 6 male and 5 female, were placed in the ELD group at age three. These 11 subjects did not meet criteria for normal expressive language at 20 to 34 months and still 
TABLE III

GROUP DESCRIPTION: AGE FOUR

\begin{tabular}{|c|c|c|c|}
\hline Group & $\underline{\mathrm{n}}$ & $\begin{array}{l}\text { Mean and } \\
\text { ( } \mathrm{SD} \text { ) Age } \\
\text { in Months }\end{array}$ & $\%$ Male \\
\hline Normal (NL) & 22 & $(2.4)$ & $59 \%$ \\
\hline History of Delay (HELD-4) & $12(63 \%)$ & $(1.6)$ & $75 \%$ \\
\hline Delayed (ELD-4) & $7(37 \%)$ & $(2.4)$ & $57 \%$ \\
\hline
\end{tabular}


did not meet normal language criteria at age three according to DSS scoring (Lee, 1974). (See Table IV.) At age four, $6(75 \%)$ of the subjects placed in the HELD group at age three, retained this placement. These children, who used fewer than 50 words at 20 to 34 months scored above tenth percentile on the DSS at both ages three and four. Fifty-five percent $(n=6)$ of the subjects in the ELD-3 group moved from the ELD group at age three to the HELD group at age four. These subjects, who also produced less than 50 words at 20 to 34 months, improved their DSS scores from below the tenth percentile at age three to above it at age four. Forty-five percent $(n=5)$ of the subjects who produced fewer than 50 words at 20 to 34 months and who scored below the tenth percentile at age three continued to score below this level at age four. Two subjects in the HELD-3 group scored below the tenth percentile on the DSS at age four.

The group placement for the four year olds is totalled in Table IV. It is as follows: 12 subjects were in the history of delay group ( 9 male, 3 female) and 7 subjects were placed in the ELD group ( 4 male, 3 female). The 22 subjects in the normal group all scored above the tenth percentile on the DSS at both ages three and four. 
TABLE IV

SUBJECTS BY GROUP ASSIGNMENT:

AGE THREE AND AGE FOUR

\begin{tabular}{|c|c|c|c|}
\hline $\begin{array}{l}\text { Subject } \\
\text { Number }\end{array}$ & $\begin{array}{l}\text { Group at } \\
\text { Age Three }\end{array}$ & $\begin{array}{l}\text { Group at } \\
\text { Age Four }\end{array}$ & $\begin{array}{l}\text { Male/ } \\
\text { Female }\end{array}$ \\
\hline 006 & HELD & HELD & $\mathrm{M}$ \\
\hline 007 & ELD & HELD & $\mathbf{M}$ \\
\hline 009 & $\mathbf{N}$ & $\mathbf{N}$ & $\mathbf{M}$ \\
\hline 019 & ELD & HELD & $F$ \\
\hline 029 & ELD & ELD & $F$ \\
\hline 036 & $\mathrm{~N}$ & $\mathrm{~N}$ & $F$ \\
\hline 040 & $\mathrm{~N}$ & $\mathbf{N}$ & $F$ \\
\hline 050 & $\mathrm{~N}$ & $\mathrm{~N}$ & $M$ \\
\hline 053 & HELD & HELD & M \\
\hline 055 & $\mathrm{~N}$ & $\mathrm{~N}$ & $F$ \\
\hline 056 & $\mathrm{~N}$ & $\mathrm{~N}$ & $F$ \\
\hline 057 & ELD & HELD & $F$ \\
\hline 058 & $\mathrm{~N}$ & $\mathrm{~N}$ & M \\
\hline 059 & $\mathrm{~N}$ & $\mathrm{~N}$ & $F$ \\
\hline 063 & $\mathrm{~N}$ & $\mathrm{~N}$ & $\mathrm{M}$ \\
\hline 072 & $\mathrm{~N}$ & $\mathrm{~N}$ & $\mathrm{M}$ \\
\hline 081 & $\mathrm{~N}$ & $\mathrm{~N}$ & $F$ \\
\hline 085 & ELD & ELD & $\mathrm{M}$ \\
\hline 086 & ELD & HELD & $\mathbf{M}$ \\
\hline 087 & HELD & HELD & $\mathbf{M}$ \\
\hline 092 & HELD & ELD & $\mathrm{M}$ \\
\hline 101 & HELD & HELD & $F$ \\
\hline 102 & ELD & HELD & $\mathrm{M}$ \\
\hline 105 & HELD & HELD & $\mathbf{M}$ \\
\hline 109 & HELD & HELD & $M$ \\
\hline 111 & ELD & ELD & $F$ \\
\hline 113 & $\mathrm{~N}$ & $\mathrm{~N}$ & $F$ \\
\hline 114 & ELD & HELD & $M$ \\
\hline 115 & ELD & ELD & $M$ \\
\hline 119 & HELD & ELD & $M$ \\
\hline 122 & ELD & ELD & $F$ \\
\hline 128 & $\mathrm{~N}$ & $\mathrm{~N}$ & $M$ \\
\hline 130 & $\mathrm{~N}$ & $\mathrm{~N}$ & $M$ \\
\hline 131 & $\mathrm{~N}$ & $\mathrm{~N}$ & $M$ \\
\hline 132 & $\mathrm{~N}$ & $\mathrm{~N}$ & $\mathbf{M}$ \\
\hline 133 & $\mathrm{~N}$ & $\mathrm{~N}$ & $\mathrm{M}$ \\
\hline 138 & $\mathrm{~N}$ & $\mathrm{~N}$ & $M$ \\
\hline 139 & $\mathrm{~N}$ & $\mathrm{~N}$ & $F$ \\
\hline 141 & $\mathrm{~N}$ & $\mathrm{~N}$ & $\mathbf{M}$ \\
\hline 144 & $\mathrm{~N}$ & $\mathrm{~N}$ & $\mathbf{M}$ \\
\hline 150 & $\mathrm{~N}$ & $\mathrm{~N}$ & $F$ \\
\hline
\end{tabular}


TABLE IV

SUBJECTS BY GROUP ASSIGNMENT:

AGE THREE AND AGE FOUR

(continued)

Totals:

Age 3

Age 4

Normal Group:

$n=22$

$\mathrm{n}=22$

$59 \%$ male

$59 \%$ male

$41 \%$ female

$41 \%$ female

HELD Group:

$\mathrm{n}=8$

$\mathrm{n}=12$

$88 \%$ male

$75 \%$ male

$12 \%$ female

$25 \%$ female

ELD Group:

$\mathrm{n}=11$

$54 \%$ male

$46 \%$ female $\mathrm{n}=7$

$57 \%$ male

$43 \%$ female 


\section{RELIABILITY}

Graduate students in the speech and Hearing Sciences Program were selected and trained to complete all reliability computations. Ten percent of the audiotapes of speech samples collected at the three year evaluation were randomly selected. These tapes were each independently transcribed by a second graduate research assistant. Reliability of transcription was computed by comparing words contained on the two transcriptions of each tape. Point to point reliability (McReynolds and Kearns, 1983) for the transcripts taken at age three was $91 \%$. The same procedure was followed for computing transcription reliability from the four-year olds' transcripts. For these, point to point reliability was $97 \%$.

Reliability of DSS scoring was done by having a trained graduate student independently rescore the DSS for a randomly selected ten percent of the transcripts collected at each age level (three years and four years). Again, point to point reliability was used to compare the number of DSS points awarded by the two scorers for each transcripts. Reliability of DSS scoring was $89 \%$ for the three year transcripts and $91 \%$ for the four year transcripts.

\section{Research Design}

A complex group design was utilized for this study. The independent variable is the language diagnosis. Three 
levels to this independent variable were formed. They are: normal developing, history of language delay, and expressive language delayed. The eight dependent variables are the DSS category subscores: indefinite pronouns, personal pronouns, main verbs, secondary verbs, negatives, conjunctions, interrogative reversals, and Wh-Questions.

\section{Statistics}

Raw scores for each subject for each DSS category (indefinite pronouns or modifiers, personal pronouns, main verbs, secondary verbs, negatives, conjunctions, interrogative reversals, and Wh questions) was summed. The means, standard deviations, and range of scores for each of the three diagnostic groups was computed for each age (three and four years). These mean scores were then compared for each DSS category among the three groups using an analysis of variance (ANOVA) to determine whether significant differences existed between the performance of the groups. If the $\underline{F}$ value was significant, a post-hoc comparison was done using the Tukey Test to determine where differences existed between groups. In addition, the means and standard deviations for all DSS scores and total DSS points was also computed. 
CHAPTER IV

RESULTS AND DISCUSSION

RESULTS

The hypothesis of this study was that significant differences would be found in the personal pronoun, main verb, secondary verb, and interrogative reversal subscores of the Developmental sentence Scoring (NSS) between normal, history of language delayed, and delayed groups at age three and again at age four. It was expected that the significant differences would be found between the groups at each of the two ages.

The research question was: if significant differences exist in DSS subscores between the three diagnostic groups, can a pattern of deficit be identified in any of the DSS syntactic categories and do any of these deficits remain constant over time?

The means and standard deviations for each DSS subscore within each language group have been computed and are displayed on Table $\mathrm{V}$ for the three year olds and on Table VI for the four year olds. The mean DSS scores and mean DSS total points for each group have also been computed and are displayed on Table VII for the three year olds and Table VIII for the four year olds. 
TABLE V

MEAN, STANDARD DEVIATION AND RANGE OF SCORES

FOR EACH GROUP ON EACH DSS CATEGORY: AGE THREE

\begin{tabular}{|c|c|c|c|c|c|}
\hline DSS Category & Group & Mean & $\underline{S D}$ & Minimum & Maximum \\
\hline \multirow{3}{*}{$\begin{array}{l}\text { Indefinite } \\
\text { Pronouns }\end{array}$} & Normal & 45.3 & 21.4 & 12.0 & 110.0 \\
\hline & HELD-3 & 32.1 & 10.1 & 13.0 & 45.0 \\
\hline & ELD-3 & 13.7 & 11.6 & 1.0 & 37.0 \\
\hline \multirow{3}{*}{$\begin{array}{l}\text { Personal } \\
\text { Pronouns }\end{array}$} & Normal & 63.3 & 24.8 & 23.0 & 119.0 \\
\hline & HELD - 3 & 36.9 & 17.7 & 15.0 & 73.0 \\
\hline & ELD-3 & 26.0 & 16.4 & 2.0 & 58.0 \\
\hline \multirow[t]{3}{*}{ Main Verbs } & Normal & 84.5 & 24.1 & 44.0 & 162.0 \\
\hline & HELD - 3 & 53.5 & 17.3 & 34.0 & 84.0 \\
\hline & ELD-3 & 26.1 & 17.7 & 2.0 & 69.0 \\
\hline \multirow[t]{3}{*}{ Secondary Verbs } & Normal & 30.0 & 12.8 & 8.0 & 59.0 \\
\hline & HELD-3 & 9.3 & 8.9 & 0.0 & 25.0 \\
\hline & ELD-3 & 4.6 & 6.9 & 0.0 & 23.0 \\
\hline
\end{tabular}


TABLE V

MEAN, STANDARD DEVIATION AND RANGE OF SCORES

FOR EACH GROUP ON EACH DSS CATEGORY: AGE THREE

(continued)

\begin{tabular}{|c|c|c|c|c|c|}
\hline DSS Category & Group & Mean & $\underline{\mathrm{SD}}$ & Minimum & Maximum \\
\hline \multirow[t]{3}{*}{ Negatives } & Normal & 17.9 & 11.6 & 4.0 & 52.0 \\
\hline & HELD-3 & 13.0 & 6.7 & 5.0 & 24.0 \\
\hline & ELD-3 & 6.0 & 6.5 & 0.0 & 20.0 \\
\hline \multirow[t]{3}{*}{ Conjunctions } & Normal & 12.0 & 10.4 & 0.0 & 38.0 \\
\hline & HELD - 3 & 4.5 & 6.1 & 0.0 & 17.0 \\
\hline & ELD-3 & .2 & .9 & 0.0 & 3.0 \\
\hline \multirow[t]{3}{*}{$\begin{array}{l}\text { Interrogative } \\
\text { Reversals }\end{array}$} & Normal & 12.3 & 9.3 & 0.0 & 34.0 \\
\hline & HELD-3 & 7.0 & 13.9 & 0.0 & 41.0 \\
\hline & ELD-3 & 1.6 & 3.6 & 0.0 & 12.0 \\
\hline \multirow[t]{3}{*}{ Wh-Questions } & Normal & 10.3 & 7.0 & 2.0 & 29.0 \\
\hline & HELD-3 & 10.8 & 13.1 & 0.0 & 36.0 \\
\hline & ELD-3 & 3.0 & 3.6 & 0.0 & 11.0 \\
\hline
\end{tabular}


TABLE VI

MEAN, STANDARD DEVIATION AND RANGE OF SCORES

FOR EACH GROUP ON EACH DSS CATEGORY: AGE FOUR

\begin{tabular}{|c|c|c|c|c|c|}
\hline DSS Category & Group & Mean & $\underline{S D}$ & Minimum & Maximum \\
\hline \multirow{3}{*}{$\begin{array}{l}\text { Indefinite } \\
\text { Pronouns }\end{array}$} & Normal & 42.8 & 18.2 & 14.0 & 80.0 \\
\hline & HELD-4 & 49.9 & 20.0 & 20.0 & 84.0 \\
\hline & ELD-4 & 38.4 & 15.0 & 27.0 & 71.0 \\
\hline \multirow{3}{*}{$\begin{array}{l}\text { Personal } \\
\text { Pronouns }\end{array}$} & Normal & 66.1 & 28.0 & 13.0 & 125.0 \\
\hline & HELD-4 & 77.8 & 20.9 & 32.0 & 98.0 \\
\hline & ELD-4 & 45.4 & 20.9 & 13.0 & 60.0 \\
\hline \multirow[t]{3}{*}{ Main Verbs } & Normal & 98.0 & 31.2 & 27.0 & 167.0 \\
\hline & HELD-4 & 92.4 & 25.3 & 50.0 & 138.0 \\
\hline & ELD-4 & 59.9 & 20.9 & 26.0 & 85.0 \\
\hline \multirow[t]{3}{*}{ Secondary Verbs } & Normal & 28.1 & 14.7 & 0.0 & 56.0 \\
\hline & HELD - 4 & 22.1 & 15.0 & 2.0 & 49.0 \\
\hline & ELD-4 & 15.1 & 12.0 & 0.0 & 39.0 \\
\hline
\end{tabular}


TABLE VI

MEAN, STANDARD DEVIATION AND RANGE OF SCORES

FOR EACH GROUP ON EACH DSS CATEGORY: AGE FOUR (continued)

\begin{tabular}{|c|c|c|c|c|c|}
\hline DSS Category & Group & Mean & $\underline{S D}$ & Minimum & Maximum \\
\hline \multirow[t]{3}{*}{ Negatives } & Normal & 15.2 & 10.1 & 0.0 & 35.0 \\
\hline & HELD - 4 & 20.8 & 13.3 & 3.0 & 51.0 \\
\hline & ELD-4 & 8.1 & 6.5 & 3.0 & 19.0 \\
\hline \multirow[t]{3}{*}{ Conjunctions } & Norma 1 & 34.3 & 27.3 & 0.0 & 115.0 \\
\hline & HELD-4 & 31.7 & $15 \cdot 3$ & 3.0 & 61.0 \\
\hline & ELD-4 & 11.5 & 8.6 & 0.0 & 24.0 \\
\hline \multirow[t]{3}{*}{$\begin{array}{l}\text { Interrogative } \\
\text { Reversals }\end{array}$} & Normal & 15.1 & 14.1 & 0.0 & 47.0 \\
\hline & HELD - 4 & 11.3 & 12.0 & 0.0 & 44.0 \\
\hline & ELD-4 & 9.9 & 12.7 & 0.0 & 34.0 \\
\hline \multirow[t]{3}{*}{ Wh-Questions } & Norma 1 & 12.9 & 11.8 & 0.0 & 46.0 \\
\hline & HELD-4 & 9.0 & 5.3 & 2.0 & 19.0 \\
\hline & ELD-4 & 7.7 & 10.4 & 0.0 & 27.0 \\
\hline
\end{tabular}


TABLE VII

MEAN DSS SCORES AND MEAN DSS TOTAL POINTS

FOR EACH GROUP: AGE THREE

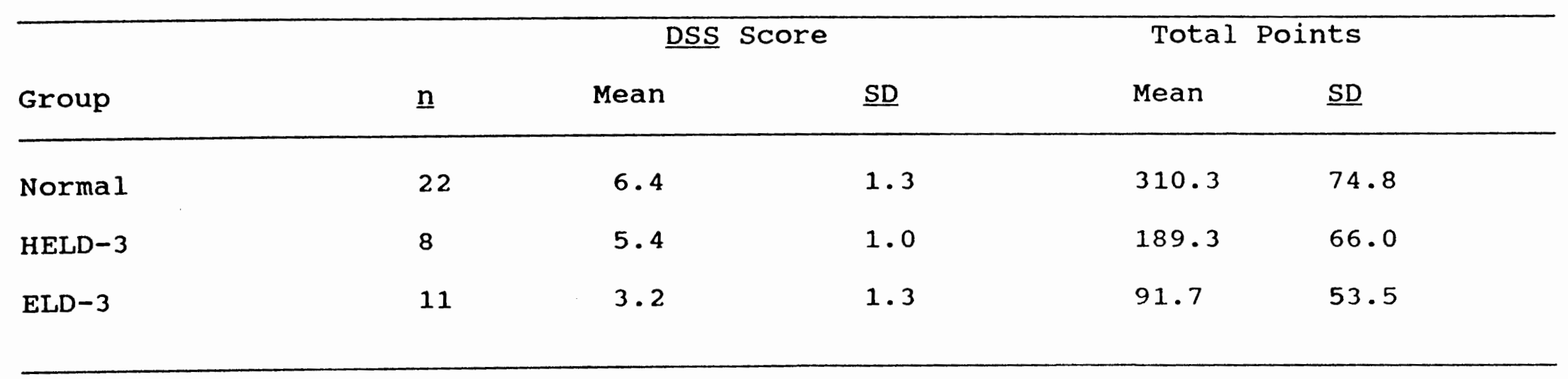




\section{TABLE VIII}

MEAN DSS SCORES AND MEAN DSS TOTAL POINTS FOR EACH GROUP: $\overline{A G E}$ FOUR

\begin{tabular}{|c|c|c|c|c|c|}
\hline \multirow[b]{2}{*}{ Group } & \multirow[b]{2}{*}{$\underline{\mathbf{n}}$} & \multicolumn{2}{|c|}{$\underline{\text { DSS Score }}$} & \multicolumn{2}{|c|}{ Total Points } \\
\hline & & Mean & $\underline{S D}$ & Mean & $\underline{S D}$ \\
\hline Normal & 22 & 7.5 & 1.2 & 349.7 & 95.9 \\
\hline HELD-4 & 12 & 7.5 & 1.2 & 347.1 & 60.0 \\
\hline ELD-4 & 7 & 5.1 & .7 & 229.3 & 59.1 \\
\hline
\end{tabular}


The data were then analyzed to determine if significant differences existed in syntactic ability between the normal language group, the history of language delay group, and the expressive language delayed group. This analysis would then serve to answer the research question. (See Tables IX and X.)

Lee (1974) recommended that fifty sentences be used when utilizing the DSS as a measure of syntactic development. However, during the present study, it was not possible to obtain a full fifty sentences from each subject. Therefore, speech samples were still analyzed according to DSS criteria. The total score was divided by the total number of sentences in the speech sample, even though a few subjects expressed less than fifty sentences. At age three, only $5 \%$ of the subjects uttered less than fifty sentences. All subjects in the normal and the HELD-3 groups expressed fifty sentences. One subject in the ELD-3 group expressed less than fifty sentences. At age four, $17 \%$ of the subjects uttered less than fifty sentences. Two subjects in the normal group and two subjects in ELD-4 group expressed less than fifty sentences. Three subjects in the HELD-4 group expressed less than fifty sentences. Total points were divided by the total number of sentences to obtain a DSS score. 
TABLE IX

ANOVA AND TUKEY TEST RESULTS: AGE THREE.

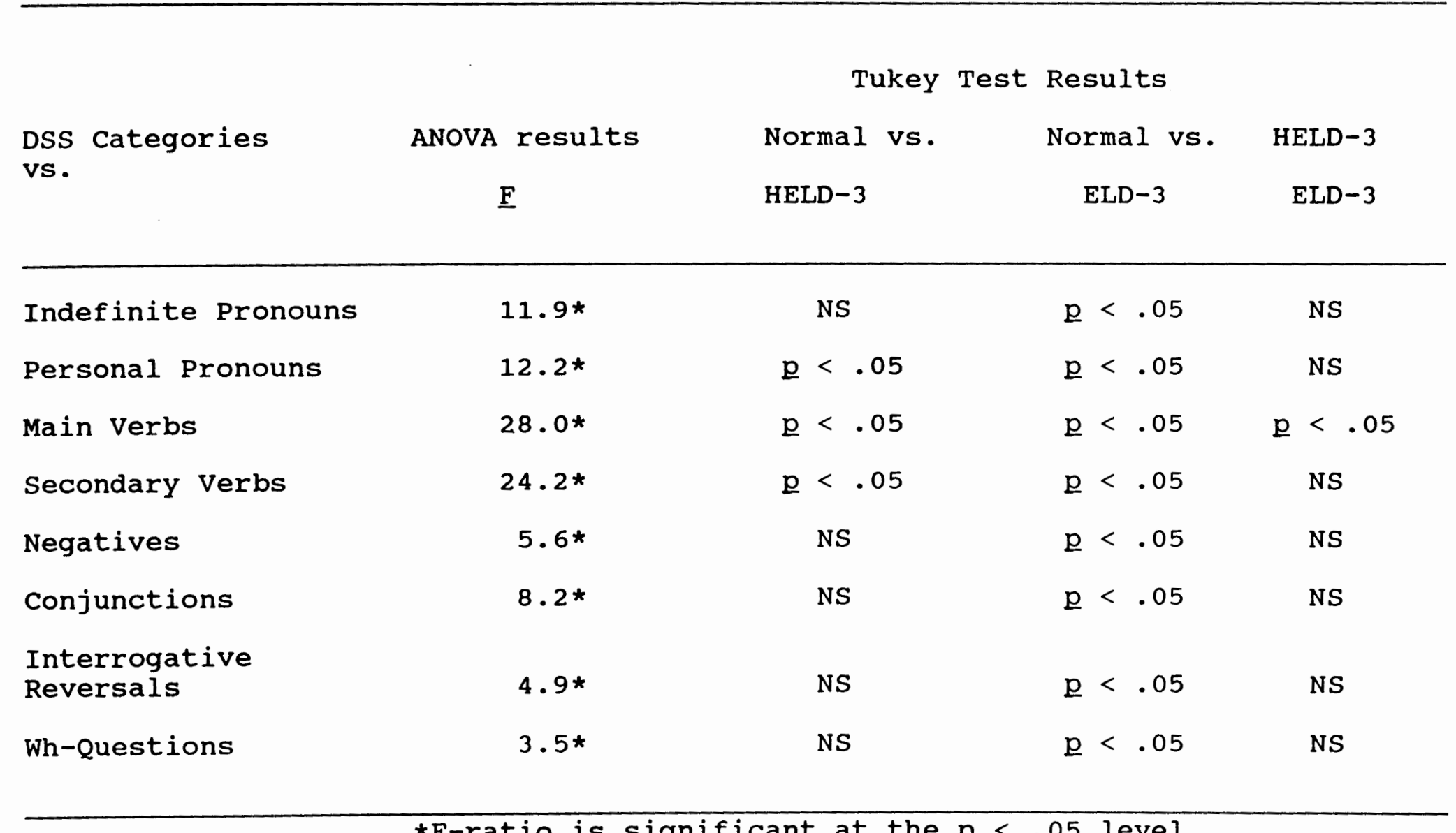


TABLE X

ANOVA AND TUKEY TEST RESULTS: AGE FOUR

\begin{tabular}{|c|c|c|c|c|c|}
\hline DSS Categories & $\begin{array}{c}\text { ANOVA results } \\
\underline{F}\end{array}$ & $\begin{array}{l}\text { Tukey } \\
\text { Normal vs. } \\
\text { HELD -4 }\end{array}$ & $\begin{array}{l}\text { Results } \\
\text { Normal vs. } \\
\text { ELD-4 }\end{array}$ & $\begin{array}{c}\text { HELD-4 } \mathrm{V} \\
\text { ELD-4 }\end{array}$ & vs. \\
\hline Indefinite Pronouns & .9 & NS & NS & NS & \\
\hline Personal Pronouns & $3.8 *$ & NS & NS & $\underline{p}<.05$ & \\
\hline Main Verbs & $4.9 *$ & NS & $\mathrm{p}<.05$ & NS & \\
\hline Secondary Verbs & $2 \cdot 3$ & NS & NS & NS & \\
\hline Negatives & $3.1 *$ & NS & NS & $\mathrm{p}<.05$ & \\
\hline Conjunctions & 2.9 & NS & NS & NS & \\
\hline $\begin{array}{l}\text { Interrogative } \\
\text { Reversals }\end{array}$ & .6 & NS & NS & NS & \\
\hline Wh-Questions & .9 & NS & NS & NS & \\
\hline
\end{tabular}

* F-ratio is significant at the $\mathrm{p}<.05$ level 
Developmental sentence scoring Categories

Significant differences are displayed on Table IX and Table $\mathrm{X}$.

\section{Indefinite Pronouns - Age Three}

A significant difference was found ( $\mathrm{p}<.05)$ among groups at age three. The Tukey Test revealed a significant difference $(\underline{p}<.05)$ between the normal group and the ELD-3 group. The normal group performed significantly better in expression of indefinite pronouns. No significant difference was found between the HELD-3 group and the ELD-3 group. No significant difference was found between the normal group and the HELD-3 group. Therefore, it is not known whether the HELD-3 group is performing more like their normal peers or like their delayed peers.

\section{Indefinite Pronouns - Age Four}

No significant differences were found among groups. This indicates that by age four the ELD-4 group "caught up" to peers and performed similarly in expression of indefinite pronouns.

\section{Personal pronouns - Age Three}

A significant difference $(\underline{p}<.05)$ was found among groups at three years of age. A Tukey Test revealed that the normal group performed significantly better than both the HELD-3 group and the ELD-3 group. This indicates that at age three, the HELD-3 group is performing more like their 
delayed peers in expressing personal pronouns than they are like normal speakers.

\section{Personal Pronouns - Age Four}

A significant difference $(\underline{p}<.05)$ was discovered among groups at four years of age. A Tukey Test showed a significant difference only between the HELD-4 group and the ELD-4 group. This suggests that by age four, the HELD-4 group "caught up" and is performing more like normal peers in use of personal pronouns, while the ELD-4 group is still lagging behind. Although the HELD-4 group scored higher on this category than the normal group, this difference was not significant.

\section{Main Verbs - Age Three}

A significant difference $(\underline{D}<.05)$ was found among groups at age three. A Tukey Test showed that a significant difference existed between the normal and the HELD-3 group. The normal language group were also significantly different from the ELD-3 group. In addition, a significant difference existed between the HELD-3 group and the ELD-3 group. This suggests that the normal group is performing significantly better the both the other groups. The history of delay group is still scoring significantly fewer points for main verbs than normal peers, but is doing significantly better in main verb use than delayed peers. 
Main verbs - Age Four

A significant difference $(\underline{p}<.05)$ was shown between the normal group and the ELD-4 group. This indicates that the delayed group is still earning significantly fewer main verb points than normal peers at age four. No significant difference was shown between the HELD-4 group and normal peers. This suggests that by age four, the HELD-4 group is increasing the complexity of use of main verbs and may be "catching up" to normal peers.

\section{Secondary verbs - Age Three}

The ANOVA revealed significant differences $(\underline{p}<.05)$ among groups. The Tukey Test found a significant difference between performance of the normal group and that of both the HELD-3 and the ELD-3 groups. No significant difference was found between ELD-3 and ELD-3 groups. This suggests that the HELD-3 group is performing similarly to the ELD-3 group in expression of secondary verbs at age three, and both are significantly behind the normals.

\section{Secondary verbs - Age Four}

No significant differences were found among groups. This indicates that by age four, the HELD-4 group and the ELD-4 group "Caught up" to their normal peers in use of secondary verbs. 


\section{Negatives - Age Three}

significant differences $(\underline{p}<.05)$ were found between the normal group and both the HELD-3 group and the ELD-3 group and there was no difference between the HELD-3 group and the ELD-3 group. At age three, the normal group performed significantly better in the area of negative production than both of the other groups. This suggest that the HELD-3 group expressed negatives similar to those of ELD-3 peers. Both the ELD-3 and the HELD-3 group are earning significantly fewer points for negative sentences than those peers that fall within the normal limits of language development.

\section{Negatives - Age Four}

Significant differences $(p<.05)$ were found among groups. The Tukey Test revealed that the ELD-4 group earned significantly fewer points for negatives than the HELD-4 group. This suggest that by age four, the HELD-4 group has "caught up" with normal peers. In fact, in this case, the HELD-4 group scored higher, though not significantly higher, than peers with normal language.

Conjunctions - Age Three

Significant differences $(\underline{p}<.05)$ were found among groups. A Tukey Test revealed that the ELD-3 group produced significantly fewer conjunctions than normal peers. The 
scores of the HELD-3 group fall midway between scores of the other two groups, and were not significantly different from either.

Conjunctions - Age Four

No significant differences among groups were identified. This suggests that the ELD-4 group "caught up" to normal peers by age four in conjunction use and that all groups are performing similarly.

\section{Interrogative reversals - Age Three}

Significant differences $(\underline{p}<.05)$ were found among groups. The Tukey Test showed that children who exhibited normal language produced significantly more sentences using interrogative reversals than those with delayed language. No significant difference was found between the children with a history of delay and those who continue to exhibit delayed language. This indicates that the HELD-3 group is not performing well enough for there to be a statistical difference from the delayed group, and not poorly enough to be performing statistically different from the normal group. HELD-3 scores fall in the mid range.

\section{Interrogative reversals - Age Four}

No significant differences were found among groups in the use of interrogative reversals at age four. All three groups performed similarly indicating that the ELD-4 group "caught up" to peers. 
Wh-Questions - Age Three

There was a significant difference among groups on the ANOVA. The Tukey Test showed a significant difference $(\mathrm{p}<.05)$ between the normal group and the ELD-3 group at age three. The normal group is using significantly more advanced Wh-Questions than the ELD-3 group. Again, the HELD-3 group's scores fall midway between those of the other two groups, and are not significantly different from either.

Wh-ouestions - Age Four

No significant differences were found when comparing use of Wh-Questions at age four. All three groups performed similarly which suggests that the ELD-4 and the HELD-4 groups "caught up" to peers with normal language abilities.

\section{DISCUSSION}

There were significant differences at age three in all eight categories of the DSS between those children identified as expressively language delayed and those identified as developing language normally. The ELD-3 group scored approximately 219 fewer total DSS points than the normal group at age three. (See Table VII.) The ELD-3 group scored fewer points across the board in all eight DSS categories at age three.

By age four, the significant differences found between the ELD-4 and normal group were concentrated in the 
main verb category. The difference in total DSS points had decreased from 219 at age three to 120 at age four. This indicates that the ELD group made progress and moved closer to the syntactic performance of the normal group. Although their overall DSS scores are still below the normal range, children classified in this study as language delayed at age four appear to be evidencing deficits only in a small set of areas measured by the DSS, primarily in verb marking. The delayed group is improving and narrowing the deficits in expressive language to a specific area of language. This area is similar to the ones identified as showing deficits in other studies of children with language delays (Rescorla and Schwartz, 1990; Leonard, 1989).

The study completed by curtiss, Katz and Tallal

(1992) found no deviant acquisition in the language impaired children. In fact, the patterns of acquisition were very similar to those displayed by children developing language normally. These findings are similar to those of the present study in that the ELD and HELD groups appeared to acquire the syntactic forms similarly, but at a slower rate suggesting a delay and not a disorder of language development.

The performance of the HELD group at age three was very similar to the performance of the ELD group at age four. The HELD group at age three had an overall number of DSS points similar to that of the normal group. However, 
despite their similarity in overall score to the normals, they did retain some deficits in verb marking of both main and secondary verbs, as well as personal pronouns. Although they appear to "catch up" on global DSS, some difficulties do persist at this age level. These difficulties appear to be overcome by age four, and the HELD group shows no differences from normal on any DSS area at that age.

The results of the present study suggest that children who continue to score below the expressive language measures at age three are less advanced than normals on all areas examined by the DSS. Three year olds with a history of slow expressive language development who score within the normal range by age three, on the other hand, differ on verb phrase development and personal pronoun development. Although these differences are restricted to a small range of DSS structures, they suggest that at age three children with a history of late talking do retain some linguistic deficits even when overall scores are within the normal range. By age four, there are no differences between the normals and the HELD group, suggesting these residual deficits are overcome by age four. The ELD-4 group appears to grow out of global deficits at age three and into more residual ones at age four. The deficits primarily in area of verb marking, with some differences in personal pronouns and negatives are similar to those retained by the HELD group at age three. There seems, then to be a consistent 
order in which deficits are "outgrown." The main difference between HELD and EID groups is the rate at which this growth takes place. The forms that present difficulties are similar to those indentified by other researchers and consist of primarily of verb phrase elaboration and use of personal pronouns.

The ELD-4 group may follow the same pattern of the HELD group and be fully caught up in another year or two. However, they may still have other deficits in areas of phonology and semantics as Scarborough and Dobrich (1990) suggest. 


\section{CHAPTER V}

SUMMARY AND IMPLICATIONS

\section{SUMMARY}

The contemporary research suggests that those children displaying early language delay in the preschool years, continued to demonstrate difficulty in achieving academically (Scarborough and Dorbrich, 1990). The current study emphasized finding specific areas of syntactic deficit displayed by subjects with delayed expressive language. The DSS is a standardized measure and includes eight areas of syntactic development. Therefore, it was utilized for the present study.

The purpose of the study was to determine if significant differences exist between three diagnostic groups in each of the eight categories of the DSS at age three and at age four. The three diagnostic groups are: 1) normal language (NL) subjects were those who at 20 to 34 months of age produced more than fifty different words by parent report on the IDS and at three and four years of age scored above the tenth percentile on the DSS; 2) history of language delay (HELD) who at 20 to 34 months were considered Late Talkers because they produced fewer than fifty different words by parent report on the LDS, but at age 
three and four scored above the tenth percentile in terms of DSS score; and 3) expressive language delayed (ELD) subjects who were Late Talkers at 20 to 34 months because they produced fewer than fifty words by parent report on the LDS and scored below the tenth percentile on the DSS at ages three and four.

Significant differences were found between the normal group and the delayed group in all DSS areas at age three, and between the normal and HELD groups on verb phrase elaboration and personal pronoun use at this age. significant differences were also found on total DSS scores between the normal and the ELD groups at age three. By age four, the ELD group's total score was closer to that of the normals, and significant differences were found only on main verb marking. There were also some differences between the HELD group and the ELD group and between the normal and the ELD groups on personal pronouns and negatives. There were no differences between normal and HELD groups at age four.

\section{IMPLICATIONS}

\section{CIinical}

Many standardized tests are used today that examine children's expressive language abilities. While these tests are sometimes useful, they do not give specific information about what areas of expressive language are in deficit. The Developmental sentence scoring technique developed by Lee 
(1974) is a useful measure in that it provides specific information regarding areas of expressive syntactic development. However, the tendency for practicing speechlanguage pathologists is not to use the DSS due to its length and complexity. A study such as this points out to the practicing clinician areas of syntax, specifically, verb marking and personal pronouns that are likely to cause problems for children with language delay. An efficient and practical use of the DSS would be for the clinician to use a tape recorded language sample to score only the categories of verb marking and personal pronouns. If scoring of these specific categories indicates a deficit, the clinician would be better informed about the possibility of a language delay and to do further testing. Being informed about the difficulties children with language delay have with verb marking and personal pronoun usage may increase the efficiency of both assessment and intervention.

\section{$\underline{\text { Research }}$}

The present study suggested that children with early language delay appear to "catch up" to normal peers in most areas of syntactic production by age four.

This study could be expanded to explore the specific verb markers and personal pronouns which are displayed by the history of delay and the delayed groups in the present study. By analyzing the word by word syntactic forms of the diagnostic groups, a comparison could be made in the main 
verb and personal pronoun categories. Leonard (1989) suggests that language impaired children display irregular past verbs like that of their normal developing peers. The specific verbs used by the subjects in the present study could be examined to find out if the subjects had difficulty with irregular vs. regular verbs.

In addition, a hypothesis could be made as to exactly which forms may be present in the repertoire of a child with a language delay, such as in the present study, and which forms may be present in the repertoire of a child with a language disorder. Consequently, by categorizing certain verb markers or personal pronouns, assessment could be made more efficient by listening for specific verb markers and personal pronouns.

Leonard (1989) states that children with specific language impairment have the most difficulty with the contractible form of the copula and auxiliary form of the verb. Although not as specific as Leonard's data, the present study contains similar findings in that verbs were problematic for the preschool child displaying an expressive language delay.

Although Leonard (1989) suggests that children with specific language impairment may have difficulties with other areas of language than morphology, he states that the speech/language impaired child displays appropriate use of a range of language areas including the area of syntactic 
structure. The present study disputes this statement. Although the preschool children with expressive language delay appear to have the ability to "catch up" with normal developing peers, the differences in syntactic structure at age three and four were significant.

Another point that Leonard (1989) makes regarding children with early language impairment is that words with "low phonetic substance" are problematic for the English speaking language impaired child (p. 187). This is an additional idea for future research. Specific words could be examined in the transcripts of the subjects in the present study to examine if the theory of "low phonetic substance" which is relevant and valid with this population. The present study has opened the door for continued research in the area of syntactic development. It is clear that in order to make language intervention more efficient, more research is necessary in all areas of language development. 


\section{REFERENCES}

Aram, D.M., Eckelman, B.L., \& Nation, J.E. (1984) . Preschoolers with language disorders: 10 years later. Journal of Speech and Hearing Research, 27, 232-244.

Aram, D.M. \& Nation, J.E. (1980). Preschool language disorders and subsequent language and academic difficulties. Journal of Communication Disorders, 13 , 159-170.

Bayley, N. (1969) - Bayley Scales of Infant Development. New York, NY: Psychological Corp.

Bishop, D.V.M. \& Edmundson, A. (1987) . Language-impaired 4-year olds: distinguishing transient from persistent impairment. Journal of Speech and Hearing Disorders, $\underline{52}$, 156-171.

Brown, R., A First Language. Cambridge, Mass.: Harvard University Press (1973).

Fundudis, T., Kolvin, I., \& Garside, R.F. (1979) . Speech Retarded and Deaf Children: Their Psychological Development. London, Academic Press.

Hall, K. \& Tomblin, J. (1978). A follow-up study of children with articulation and language disorders. Journal of Speech and Hearing Disorders, 43, 227-241.

Lee. L.L. (1974). Developmental Sentence Analysis. Evanston, IL: Northwestern University Press, 1974.

Lee. L.L. (1966). Developmental sentence types: a method for comparing normal and deviant syntactic development. Journal of Speech and Hearing Disorders, 31, (4), 311-330.

Lee, L.L. \& Canter, S. M. (1971). Developmental sentence scoring: a clinical procedure for estimating syntactic development in children's spontaneous speech. Journal of Speech and Hearing Disorders, 36, (3) 315-337.

Leonard, L. (1989) . Language learnability and specific language impairment in children. Applied

Psycholinguistics, 10, 179-202. 
Lewis, B.A. \& Freebairn, L. (1992). Residual effects of preschool phonology disorders in grade school, adolescence, and adulthood. Journal of Speech and Hearing Research, 35, 819-831.

Mason, M. (1965). Specific (developmental) dyslexia. Developmental Medicine and Child Neurology, 9, 183-190.

Maxwell, S. \& Wallach, G. (1984). The language learning disabilities connection: symptoms of early language disability change over time. In G.P. Wallach and K.G. Butler (Eds.), Language Learning Disabilities in School Age Children, 15-34.

McNeil, D. (1966). Developmental psycholinguistics. In F. Smith and G.A. Miller (Eds.), The Genesis of Language: A Psycholinguistic Approach. Cambridge, Mass.: MIT Press.

McReynolds, L. \& Kearns, M. (1983). Single subject Experimental Designs in Communication Disorders. Austin, TX: Pro-Ed.

Morehead, D.M., \& Ingram, D. (1973). The development of base syntax in normal and linguistically deviant children. Journal of Speech and Hearing Research, 16, (3), 330-334.

Myers, J.K. \& Bean, L.L. (1965). A Decade Later: A Follow-up of Social Class and Mental Illness. New York, NY: Wyley and Sons.

Paul, R. (1989). Outcomes of expressive language delay in toddlers. Paper presented at the ASHA National Convention, st. Louis, MO.

Paul, R. \& Shiffer (in press). The expression of communicative intents in normal and "late talking" young children. Applied Psycholinguistics.

Paul, R. \& Cohen, D. (1984). Outcomes of severe disorders of language acquisition. Journal of Autism and Developmental Disorders, 14, 405-422.

Rescorla, L. (1989). The language development survey. Journal of Speech and Hearing Disorders, 54, 587-599.

Rescorla, L. \& Schwartz, E. (1990). Outcome of toddlers with specific expressive language delay. Applied Psycholinguistics, 11, 393-407.

Reynell, J. (1984). Reynell Developmental Lanquage Scales. Windsor, England: NFER. 
Scarborough, H.S. (in press). Index of productive syntax. Applied Psycholinguistics.

Scarborough, H.S. \& Dobrich, W. (1990). Development of children with early language delay. Journal of Speech and Hearing Research, 33, 70-83.

Stark, R.E., Bernstein, L.E., Condino, R., Bender, M. , Talial, P., \& Catts, H. (1984). Four-year follow-up study of language impaired children. Annals of Dyslexia, 34, $49-68$. 
APPENDIX A

QUESTIONNAIRE FOR PARENTS OF

CHILDREN 15-30 MONTHS OLD 


\section{QUESTIONNAIRE FOR PARENTS OF CHILDREN IS-30 MONTUS OLD}

What is your child's:

first name?

date of birth?

Mother's (or primary parent's) full name?

Mother's (or primary parent's) phone number?

Mother's occupation?

Father's occupation?

Hoi many different words can your child say? (It's OK if the words aren't entirely clear, as long as you can understand the m.)

none $10-30$

less than rive $30-50$

$5-10$ more than 50

If your child says fewer than ten words, please list the m here:

Does your child put words together to form short "sentences"? Yes No Ii yes, please give three examples here:

Would you be interested in participating in later parts of this study? Y.S Nio 
APPENDIX B

OREGONIAN ARTICLE 


\section{Toddlers with delayed speech sought}

A Portland State University researcher is looking for otherwise normal toddlers who begin talking late to serve as subjects in a study of delayed speech and its connection, if any, to later language problems.

Rhea Paul, a PSU assistant professor of speech communication, said the reasons for delayed speech in "late-blooming" young children and the early identification of toddlers who later will suffer chronic language delay had not been well-investigated, although perhaps 10 percent of American children may fall into those categories.

Paul is interested in studying children between the ages of 18 and 30 months in the Portland-Vancouver area who can say only five or fewer words, instead of the 50 or so most children can speak by that age. She hopes to monitor their progress in speech development for two to five years, using such tools as speech tests and videotaped play sessions with their parents, to determine whether the children are indeed late-bloomers or whether their lack of early communication skills signals the start of severe speech and language delays.

Early identification of such children may allow early intervention and prevent future speech deficits, she said.

Paul's research is funded by the Fred Meyer Charitable Trust, the American Speech, Language and Hearing Foundation, and PSU. Parents who are interested in allowing their children to participate may contact Paul through the PSU Department of Speech.

The Oregonian, Portland, Oregon 
APPENDIX C

PARENT PERMISSION FORM 
I. - hereby agree to serve as a subject in the research project on language development in young children conducted by Rhea Paul.

I understand that the study involves seeing my child yearly for speech and language evaluation and audiotaping conversations between me and my child. I understand that these tapes will be transcribed for analysis of my child's spoken language patterns.

It has been explained to me that the purpose of the study is to learn whether children who begin talking late are at risk for later learning problems.

I may not receive any direct benefit from participation in this study, but my participation may help to increase knowledge which may benefit others in the future.

Dr. Paul has offered to answer any questions I may have about the study and what is expected of me in the study. I have been assured that all information I give will be kept confidential and that the identiy of all subjects will remain anonymous.

I understand that I am free to withdraw from participation in this study at any time without jeopardizing my relationship with Portland State University.

I have read and understand the foregoing information.

Date Signature

If you experience problems that are the result of your participation in this study, please contact the secretary of the Human Subjects Research and Review Committee, Office of Grants and Contracts, 303 Cramer Hall, Portland State University, $464-3417$. 
APPENDIX D

LANGUAGE DEVELOPMENT SURVEY 


\section{Language Development Survey}

Picasc check off each word that your child says SPONTANEOUSLY Inot just imitates or undersiands'

li's okay to couns words thas aren't pronounced clearly or are in "baby talk "I"baba" for bot:!e

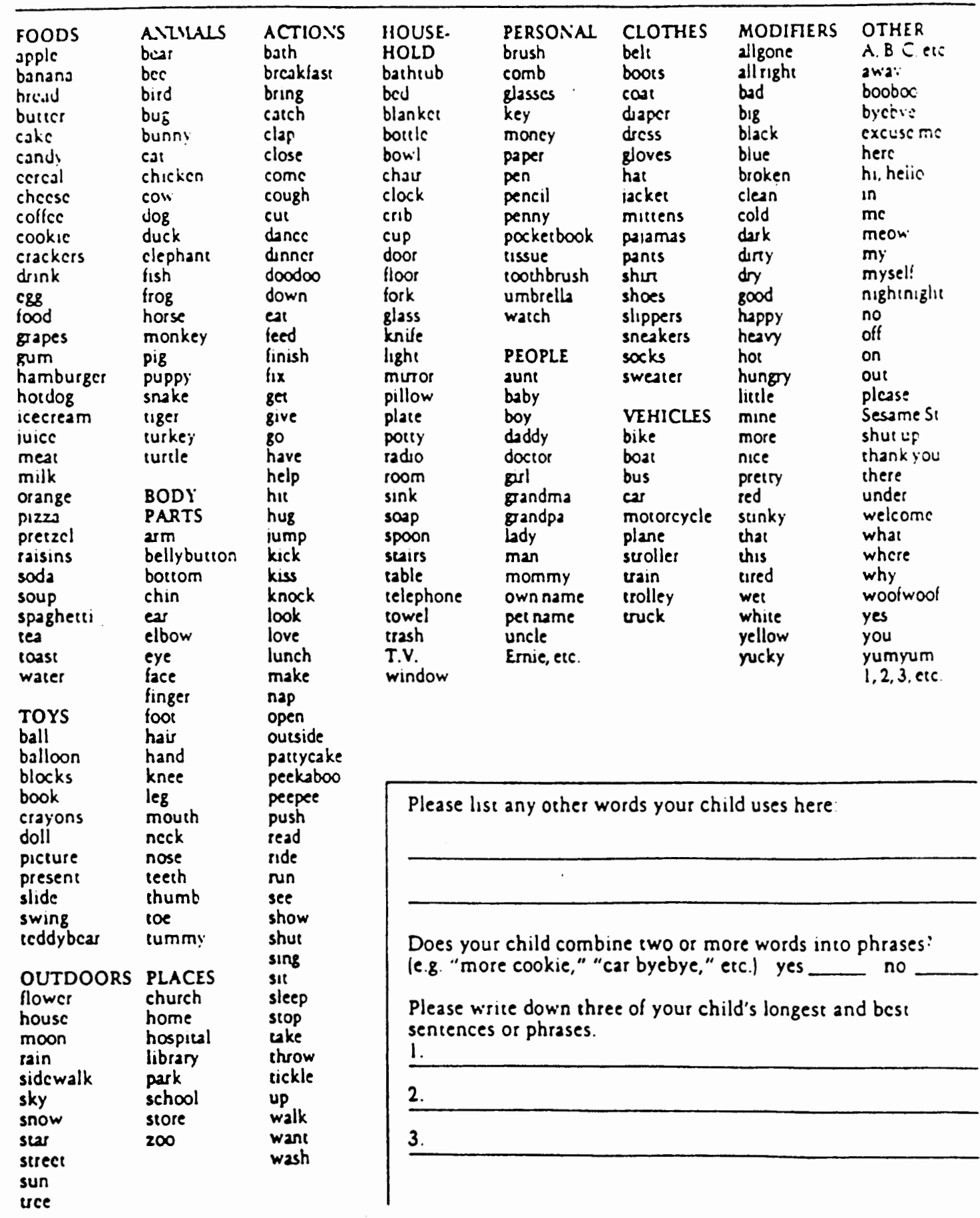




\section{APPENDIX E \\ DEVELOPMENTAL SENTENCE SCORE: \\ SCORING CRITERIA}

Source: Lee, L. (1974). Developmental sentence analysis. Evanston, IL: Northwestern University Press. 
The Developmental Sentence Scoring (DSS) Reweighted Scores

\begin{tabular}{|c|c|c|c|c|}
\hline score & $\begin{array}{l}\text { Indefinite Prosoums } \\
\text { or Noun Modifien }\end{array}$ & $\begin{array}{l}\text { Perronal } \\
\text { Prooouns }\end{array}$ & Main Verbs & Secoodary Verts \\
\hline 1 & it, this. that & $\begin{array}{l}\text { lat and 2nd person: } I \text {, me, my, } \\
\text { mine, you, your(s) }\end{array}$ & $\begin{array}{l}\text { A. Uninfected vert: } \\
\text { I see you. } \\
\text { B. copula. is or 's: } \\
\text { I's red. } \\
\text { C. is + vert + ing: He is } \\
\text { coming }\end{array}$ & \\
\hline 2 & & $\begin{array}{l}\text { 3rd pernos: he, him, his, she. } \\
\text { her, hers }\end{array}$ & $\begin{array}{l}\text { A. I and ed: ploys, played } \\
\text { B. irregular parc: } \\
\text { ate, sow } \\
\text { C. Copulz: an, are, was, were } \\
\text { D. Auxiliary am, are, was, were }\end{array}$ & 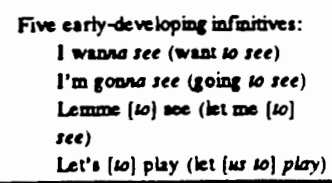 \\
\hline 3 & 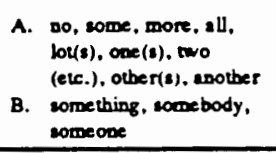 & $\begin{array}{l}\text { A. Phunt: we, us, our(s), } \\
\text { they, them, the ir } \\
\text { B. thexe, those }\end{array}$ & & $\begin{array}{l}\text { Non-complewenting infmitives: } \\
\text { I scopped wo ploy. } \\
\text { l'm afrid so look. } \\
\text { It's berd wo do that }\end{array}$ \\
\hline 4 & $\begin{array}{l}\text { vothing, nobody, noxe, po } \\
\text { oce }\end{array}$ & & $\begin{array}{l}\text { A. Can, will, mey + verb: } \\
\text { moy go } \\
\text { B. Oblipalory do + verb: } \\
\text { don't } 80 \\
\text { C. Emphatic do + verb: } \\
\text { I do exe. }\end{array}$ & $\begin{array}{l}\text { Parviciple, present of past } \\
\text { I we a boy nouring. } \\
\text { I found the roy braken. }\end{array}$ \\
\hline 5 & & $\begin{array}{l}\text { Refexives: myself, yourself, } \\
\text { himeclf, herseif, iteilf. } \\
\text { themelives }\end{array}$ & & 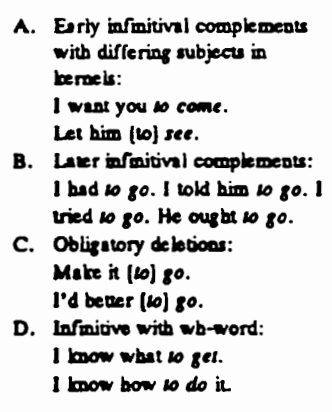 \\
\hline 6 & & 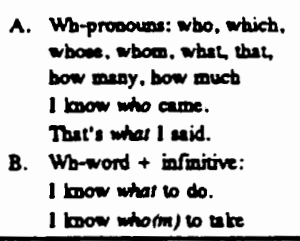 & $\begin{array}{l}\text { A. could. would, ebould, migbs } \\
\text { + wrot: } \\
\text { might come, conld be } \\
\text { B. Oblizelory does, did + vert } \\
\text { C. Emptesic does, did + vert }\end{array}$ & \\
\hline 7 & 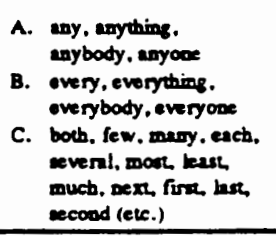 & 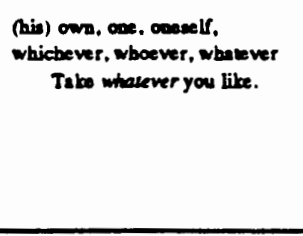 & 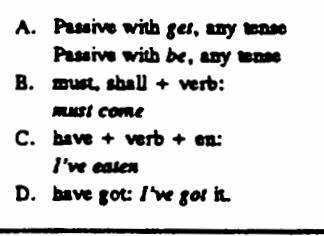 & 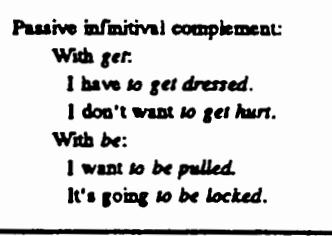 \\
\hline 8 & & & 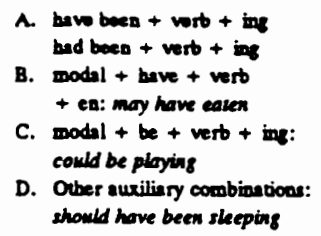 & $\begin{array}{l}\text { Oenend: } \\
\text { Swingting in fun. } \\
\text { I like forhing. } \\
\text { He marred bewghtung. }\end{array}$ \\
\hline
\end{tabular}




\begin{tabular}{|c|c|c|c|c|}
\hline Score & Negutives & Conjunctions & Interrogative Reversals & Wb-Quextions \\
\hline 1 & 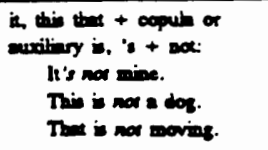 & & 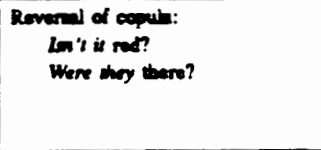 & \\
\hline 2 & & & & 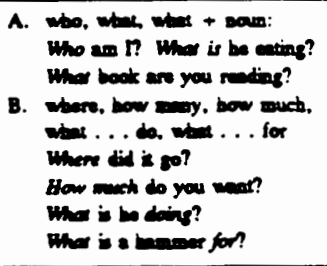 \\
\hline 3 & & $a d$ & & \\
\hline 4 & $\cosh 2$ thent & & 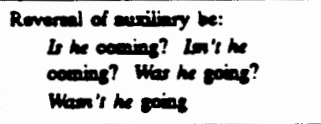 & \\
\hline 3 & ind & $\begin{array}{l}\text { A. we } \\
\text { B. } \infty ., \infty \text {, wo that } \\
\text { C. } \infty \text {, if }\end{array}$ & & 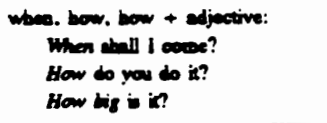 \\
\hline 6 & & becoue & 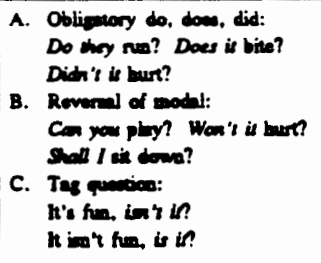 & \\
\hline 7 & 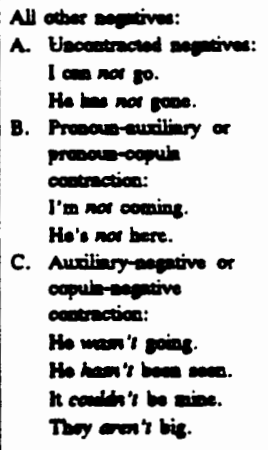 & & & 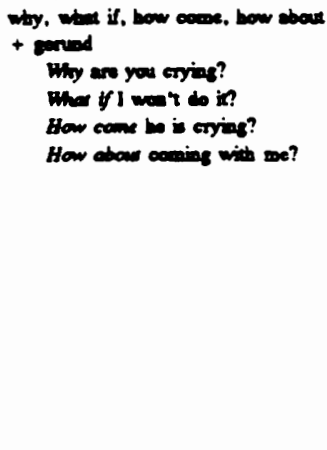 \\
\hline 8 & & 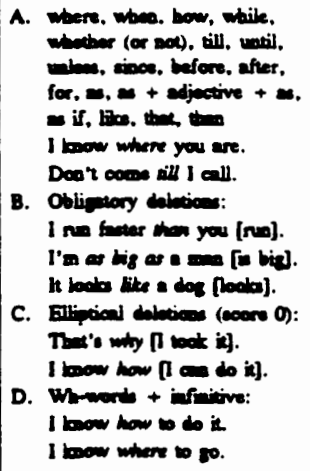 & 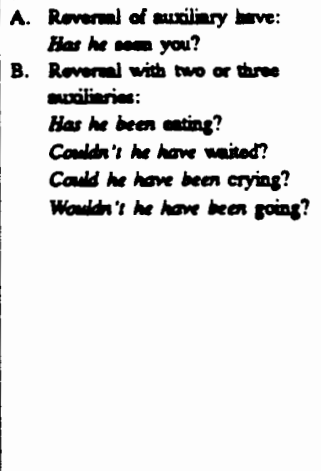 & 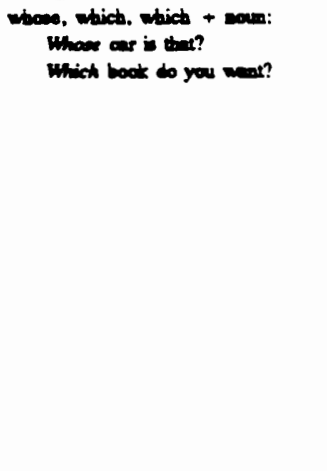 \\
\hline
\end{tabular}




\section{APPENDIX F \\ DEVELOPMENTAL SENTENCE SCORE: \\ NORMS}

Source: Lee, L. (1974). Developmental sentence analysis. Evanston, IL: Northwestern University Press. 


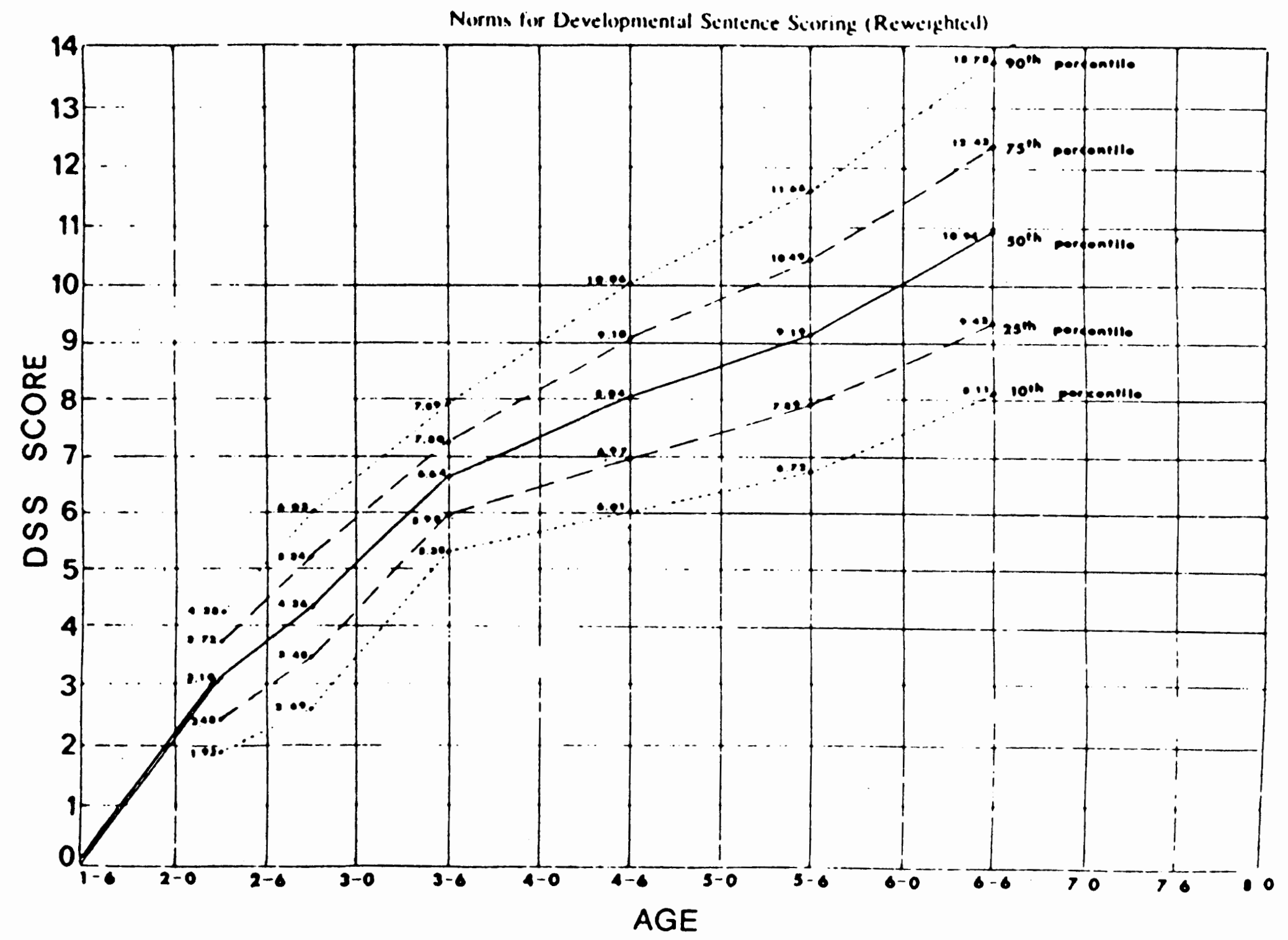


APPENDIX G

HUMAN SUBJECTS RESEARCH REVIEW COMMITTEE APPROVAL MEMO 
DATE: $\quad$ October 9,1992

TO: $\quad$ Michelle Riback

FROM: $\quad$ Martha Balshem, Chair, HSRRC 1992-93

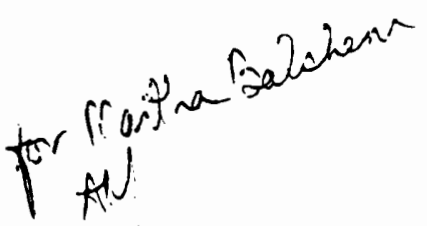

RE: $\quad$ HSRRC Approval of Your Application titled "Comparison of Developmental Sentence Score Patterns ..."

In accordance with your request, the Human Subjects Research Review Committee has reviewed your proposal referenced above for compliance with DHHS policies and regulations covering the protection of human subjects. The committee is satisfied that your provisions for protecting the rights and welfare of all subjects participating in the research are adequate, and your project is approved.

Any changes in the proposed study, or any unanticipated problems involving risk to subjects, should be reported to the Human Subjects Research Review Committee. An annual report of the status of the project is required.

c. Office of Graduate Studies

MB:am 